\title{
Article \\ Folate-Decorated Cross-Linked Cytochrome c Nanoparticles for Active Targeting of Non-Small Cell Lung Carcinoma (NSCLC)
}

\author{
Irivette Dominguez-Martinez $^{1,2}$, Freisa Joaquin-Ovalle ${ }^{1,2}\left(\mathbb{D}\right.$, Yancy Ferrer-Acosta ${ }^{3, *(\mathbb{C}}$ and Kai H. Griebenow $1, *$ (i) \\ 1 Department of Chemistry, University of Puerto Rico, San Juan 00925, Puerto Rico; \\ irivette.dominguez@upr.edu (I.D.-M.); freisa.joaquinovalle@upr.edu (F.J.-O.) \\ 2 Molecular Sciences Research Center, San Juan 00926, Puerto Rico \\ 3 Department of Neuroscience, Universidad Central del Caribe, Bayamón 00956, Puerto Rico \\ * Correspondence: yancyferrer@gmail.com (Y.F.-A.); kai.griebenow@gmail.com (K.H.G.)
}

Citation: Dominguez-Martinez, I.; Joaquin-Ovalle, F.; Ferrer-Acosta, Y.; Griebenow, K.H. Folate-Decorated Cross-Linked Cytochrome c

Nanoparticles for Active Targeting of Non-Small Cell Lung Carcinoma

(NSCLC). Pharmaceutics 2022, 14, 490.

https://doi.org/10.3390/

pharmaceutics14030490

Academic Editors: Donatella Paolino, Ana Isabel Fraguas-Sánchez and Cristina Martin-Sabroso

Received: 8 January 2022

Accepted: 20 February 2022

Published: 24 February 2022

Publisher's Note: MDPI stays neutral with regard to jurisdictional claims in published maps and institutional affiliations.

Copyright: (C) 2022 by the authors. Licensee MDPI, Basel, Switzerland. This article is an open access article distributed under the terms and conditions of the Creative Commons Attribution (CC BY) license (https:// creativecommons.org/licenses/by/ $4.0 /)$.

\begin{abstract}
The folate receptor alpha (FR), which is overexpressed in solid tumors including NSCLC, can be utilized for active tumor targeting to afford more effective cancer therapies. In this context, cytochrome c (Cyt c) has drawn attention to cancer research because it is non-toxic, yet, when delivered to the cytoplasm of cancer cells, can kill them by inducing apoptosis. Cyt c nanoparticles (NPs, $169 \pm 9 \mathrm{~nm}$ ) were obtained by solvent precipitation with acetonitrile, and stabilized by reversible homo-bifunctional crosslinking to accomplish a Cyt-c-based drug delivery system that combines stimulus-responsive release and active targeting. Cyt $\mathrm{c}$ was released under intracellular redox conditions, due to an S-S bond in the NPs linker, while NPs remained intact without any release under extracellular conditions. The NP surface was decorated with a hydrophilic folic acid-polyethylene glycol (FA-PEG) polymer for active targeting. The FA-decorated NPs specifically recognized and killed cancer cells $\left(\mathrm{IC}_{50}=47.46 \mu \mathrm{g} / \mathrm{mL}\right.$ ) that overexpressed FR, but showed no toxicity against FR-negative cells. Confocal microscopy confirmed the preferential uptake and apoptosis induction of our NPs by FR-positive cancer cells. In vivo experiments using a Lewis lung carcinoma (LLC) mouse model showed visible NP accumulation within the tumor and inhibited the growth of LLC tumors.
\end{abstract}

Keywords: cancer; crosslinker; cytochrome c; drug delivery; folate receptor; Lewis lung carcinoma; triggered release

\section{Introduction}

Lung cancer is the leading cause of worldwide cancer deaths. Non-small cell lung carcinoma (NSCLC) is the most common type of lung cancer, accounting for $85 \%$ of the reported cases, and is associated with poor prognosis-a five-year survival rate of only $15 \%[1,2]$. Although the current first-line anticancer agents (e.g., cisplatin and Taxol ${ }^{\circledR}$ ) against NSCLC have been successful to some extent, their main drawbacks are their non-specific targeting, high dose requirements, poor bioavailability, the development of multiple drug resistance, and adverse side effects [3-5]. For example, NSCLC patients treated with cisplatin often suffer severe nephrotoxicity [6]. In principle, these effects arise from the chemotherapeutic agents' lack of tumor selectivity and systemic toxicity without discriminating healthy tissues, producing unwanted and often severe and dangerous side effects.

All chemotherapeutic drugs, regardless of their specific target or mechanism of action, produce the same cytotoxic end effect in sensitive cells: cell death. However, the apoptotic DNA damage response requires the involvement of the p53 tumor suppressor pathway, which is mutated/inactivated in $~ 50 \%$ of human cancers [7] and approximately $70 \%$ of lung adenocarcinoma cases [8]. Such oncogenic mutations that disrupt the apoptosis pathway contribute to tumor initiation, progression, and metastasis [9]. For example, Taxol $^{\circledR}$ causes damage leading to p53-tumor-suppressor-dependent apoptosis and often 
results in the development of resistance, leading to therapy failure and relapse [4]. Such limitations of conventional chemical drugs have spurred efforts to identify more effective chemotherapeutic agents that can be tolerable in higher doses and act independently of the p53 pathway [10].

As an alternative approach, proteins that exhibit potent cytotoxic activities can be exploited to develop new anti-tumor drugs [11]. Cytochrome C (Cyt c) fulfills this requirement because it is non-toxic in the cytoplasm and acts downstream in the apoptosis cascade, thus evading many steps with potential mutations. During Cyt c-mediated apoptosis, the apoptosome formation (Apaf-1/Cyt c complex), which cleaves procaspase- 9 to active caspase 9, is a critical event responsible for activating effector caspases 3 and 7, which mediate apoptosis [12,13]. Indeed, using a drug delivery system to transport Cyt c into the cytoplasm of cancer cells could help overcome any failure in activating the intrinsic or 'mitochondrial' apoptotic signaling pathway that prevents Cyt c release $[10,14,15]$. Hence, Cyt $\mathrm{c}$ has drawn the attention of groups in the field for its potential to be developed into a highly effective and selective anticancer drug [13]. However, since Cyt $\mathrm{c}$ is a cell-membrane-impermeable protein, it must be linked to an uptake process.

Folic acid (FA) is a B vitamin necessary for cellular proliferation and DNA synthesis and modification [16]. The folate receptor alpha (FR) is a well-known tumor marker that is overexpressed in $40 \%$ of human cancers, and it is rarely expressed or inaccessible in most normal cells [17]. Studies have found that levels of FR expression are associated with tumor stage and survival, specifically in lung adenocarcinomas [18,19]. This overexpression in tumors promotes folic acid ligand-drug conjugates to bind and promote their subsequent uptake via receptor-mediated endocytosis [20]. Hence, FA has been extensively used as a ligand to improve tumor therapy's uptake and target cancerous cells.

One of the most influential hallmarks of cancer cells is their ability to sustain proliferative and pro-angiogenic signaling, which leads to an unstable and leaky vasculature accompanied by insufficient lymphatic drainage in tumors (the EPR effect), which drives the accumulation of nano-sized delivery systems in solid tumors [21]. The EPR effect alone increases the tumor specificity of nanoparticles (NPs) by 20-30\% over critical normal organs [22]. The polyethylene glycol (PEG) polymer has been used to modify NPs and overcome their low stability, immunogenicity, and short blood circulation half-life [23]. Combining the passive EPR-mediated targeting with an additional tumor-abundant ligand such as FA not only amplifies the specificity of therapeutic NPs, but also facilitates their cellular uptake.

For in vivo applications, shape and size are critical determinants of nanoparticle uptake and circulation $[24,25]$. Spherical particles that are 100-200 $\mathrm{nm}$ in size have the highest potential for prolonged circulation, because they are large enough to avoid uptake in the liver (particles over $300 \mathrm{~nm}$ accumulate in the liver) but small enough to prevent filtration to the spleen (as the spleen has fenestrations that do not exceed 200-500 nm) [26]. Typically, nanoparticles are trapped by mechanical filtration in the spleen sinusoids, followed by removal from circulation by the cells of the reticuloendothelial system in the liver [23].

To date, various nano vehicles have been explored to facilitate the intracellular delivery of Cyt c for therapeutic purposes with different degrees of success [27,28]. Recently, our research group overcame biocompatibility and off-target limitations commonly seen in anticancer therapeutics by designing a Cyt c-based drug delivery system (DDS) coated with a biodegradable polymer, PLGA-PEG-FA, which is $253 \mathrm{~nm}$ in size [29]. This DDS showed a tumor-targeting capability and no cytotoxicity after an in vivo injection using a lung carcinoma immune-competent mouse model [29].

Herein we substantially simplify the system by employing another strategy for preventing protein dissolution in buffer and blood, which uses redox-sensitive crosslinking. Cyt c NPs were prepared by solvent precipitation. Protein nanoprecipitation is an easy and reproducible technique to prepare Cyt c NPs. Their size, shape, and surface charge can be controlled to incorporate passive, active, and stimuli-responsive targeting [30]. Next, the Cyt c-based NPs were stabilized by homo-bifunctional reversible crosslinking using 
dithiobis(succinimidyl propionate) (DSP). This crosslinker contains a disulfide bond that is reduced under intra-cellular conditions, thus affording the dissolution of the NPs in the cytoplasm of target cells. To achieve receptor-mediated internalization by FR-overexpressing cancer cells, we conjugated folate-poly(ethylene glycol) (FA-PEG) to the surface of the NPs. Our data demonstrate a substantial improvement over our previous Cyt c delivery system both in vitro, using the Lewis lung carcinoma (LLC) cell line, and in vivo, using the LLC mouse model. This mouse model is a practical in vivo approach to study drug safety and test whether targeted NP therapies reach their target in the presence of a functional immune system [31].

\section{Materials and Methods}

\subsection{Materials}

Cyt $c$ from the equine heart ( $\geq 95 \%$ purity), acetonitrile, dithiobis(succinimidyl propionate) (DSP) crosslinker, L-glutathione (reduced, $\geq 98.0 \%$ purity), and isomer I of fluorescein isothiocyanate (FITC) were obtained from Sigma-Aldrich (St. Louis, MO, USA). Folatepoly(ethylene glycol)-succinimidyl ester (FA-PEG-NHS, $\mathrm{M}_{\mathrm{W}} 3400 \mathrm{Da}$ ) was purchased from Biochempeg Scientific Inc. (Watertown, MA, USA). CellTiter 96 aqueous non-radioactive cell proliferation assay was purchased from Promega Corporation (Madison, WI, USA). Ampilite $^{\mathrm{TM}}$ Colorimetric Caspase 3/7 Assay Kit was purchased from AAT Bioquest (Sunnyvale, CA, USA). DAPI (4',6-diamidino-2-phenylindole, NucBlue $\left.{ }^{\circledR}\right)$, FM-464 membrane stain, propidium iodide (PI), and CellEvent ${ }^{\mathrm{TM}}$ Caspase-3/7 Green was obtained from Invitrogen (Eugene, OR, USA). Near-infrared reactive dye IRDye ${ }^{\circledR}$ 680RD was available as a protein labeling kit (high molecular weight) from LI-COR Biosciences.

\subsection{Synthesis of Cross-Linked Cyt c-PEG-FA Nanoparticles}

Crosslinked Cyt c-PEG-FA NPs were synthesized by first obtaining protein NPs using a nanoprecipitation method [29]. Briefly, $5 \mathrm{mg} / \mathrm{mL}$ of Cyt c dissolved in ultrapure water was solvent-precipitated by adding acetonitrile at a 1:4 (water/acetonitrile) volume ratio at a constant rate of $300 \mathrm{~mL} / \mathrm{h}$ using an automated syringe pump. The NP suspension was left stirring for $5 \mathrm{~min}$. Subsequently, the resulting Cyt c NP suspension was covalently stabilized by directly adding $0.2 \mathrm{mg} / \mathrm{mL}$ of the homo-bifunctional DSP crosslinker dissolved in acetonitrile. After $30 \mathrm{~min}$ under constant stirring at room temperature, $7 \mathrm{mg} / \mathrm{mL}$ of FAPEG-NHS (MW $3400 \mathrm{Da}$ ) polymer dissolved in a mixture of 3:1 acetonitrile/ultrapure water was added to the NP suspension and was allowed to react at room temperature for $18 \mathrm{~h}$. The NPs were subsequently centrifugated at 10,000 rpm and washed thrice with ultrapure water. These NPs were then flash-frozen and freeze-dried.

\subsection{Determination of Precipitation Efficiency and Actual Protein Loading}

To calculate precipitation efficiency and actual drug loading, an aliquot of $10 \mu \mathrm{L}$ was collected right before nanoprecipitation to determine the initial amount of Cyt c. After nanoprecipitation, the NP suspension was centrifuged for $10 \mathrm{~min}$ at 10,000 rpm at room temperature. The concentrations of Cyt $\mathrm{c}$ in the aliquot and supernatants were determined by measuring the absorbance at $410 \mathrm{~nm}$ using a NanoDrop 2000c (Thermo Scientific, Waltham, MA, USA) [32]. The final amount of NP was obtained by weighing the final product. Precipitation efficiency (EE) and actual protein loading (AL) were calculated using the following equations:

$$
\begin{gathered}
\mathrm{EE}(\%)=\frac{\text { initial amount of Cyt c }- \text { Cyt c in supernatant }}{\text { initial amount of Cyt c }} \times 100 \\
\mathrm{AL}(\%)=\frac{\mathrm{mg} \text { of Cyt c in nanoparticles }}{\mathrm{mg} \text { of nanoparticles }} \times 100
\end{gathered}
$$

The experiments were performed in triplicate, averaged, and standard deviations (SD) were calculated. 


\subsection{Dynamic Light Scattering (DLS)}

Particle size, polydispersity index (PDI), and zeta potential of Cyt c NPs, crosslinked Cyt c NPs, and crosslinked Cyt c-PEG-FA NPs were determined by dynamic light scattering (DLS) using a Zetasizer Nano ZS (Malvern Panalytical Ltd., Malvern, UK). The samples were dispersed in ultrapure water and subjected to ultrasonication at $240 \mathrm{~W}$ for $30 \mathrm{~s}$ before the measurements. NPs were transferred to capillary cells for zeta potential determination. The experiments were performed in triplicate, and the results were expressed as the mean $\pm \mathrm{SD}$.

\subsection{Scanning Electron Microscopy (SEM)}

SEM micrographs of crosslinked Cyt c-PEG-FA NPs were performed using a JEOL 6480LV scanning electron microscope at $20 \mathrm{kV}$. Lyophilized NPs were coated with gold for $10 \mathrm{~s}$ using an auto sputter coater (108 Auto/SE, Ted Pella Inc., Redding, CA, USA).

\subsection{In Vitro Release}

To determine the in vitro Cyt c release profile of NPs, $0.5 \mathrm{mg} / \mathrm{mL}$ of crosslinked Cyt c-PEG-FA NPs were suspended in PBS buffer ( $\mathrm{pH}$ 7.4) with glutathione (GSH) concentrations of $0,0.001$, and $10 \mathrm{mM}$ simulating extra- and intracellular conditions [33]. The NPs were incubated at $37^{\circ} \mathrm{C}$ under constant stirring for various time intervals: $0.5,2.5,20,30$, and $46 \mathrm{~h}$. At predetermined time points, NPs were centrifuged at $14,000 \mathrm{rpm}$ for $10 \mathrm{~min}$, and the supernatant was collected and replaced with an equal volume of PBS/GSH buffer. The supernatant was used to determine the concentration of released Cyt $\mathrm{c}$ by UV-vis spectroscopy using a NanoDrop 2000c (Thermo Scientific, Waltham, MA, USA). The wavelength used to measure the concentration of non-reduced Cyt c ( $0 \mathrm{mM}$ and $0.001 \mathrm{mM} \mathrm{GSH})$ was $530 \mathrm{~nm}$, and reduced Cyt c (10 mM GSH) was $550 \mathrm{~nm}$ [29]. The amount of released Cyt c from the NPs to the PBS/GSH dissolvent (observed at $550 \mathrm{~nm}$ ) was used to construct cumulative Cyt c release profiles at incrementally higher reducing conditions using GSH as the reducing agent. The experiments were performed in triplicate, the results averaged, and the standard deviations calculated.

\subsection{Cell-Free Caspase 3/7 Activity Assay}

Caspase activation by Cyt $\mathrm{c}$ was measured in LLC cell lysate following the procedure previously reported in the literature [29]. Briefly, $5 \times 10^{6}$ LLC cells were resuspended in $100 \mu \mathrm{L}$ of lysis buffer, and cells were lysed with four freeze-thaw cycles using liquid nitrogen and a water bath at $37^{\circ} \mathrm{C}$. Then, the cell lysate was centrifuged at $11,000 \mathrm{rpm}$ for $20 \mathrm{~min}$ at $4{ }^{\circ} \mathrm{C}$, and the supernatant (lysate) was collected. For the caspase $3 / 7$ cell-free reaction, the obtained lysate was mixed with $300 \mu \mathrm{g} / \mathrm{mL}$ of crosslinked Cyt c-PEG-FA NPs using a volume ratio of 1:1 (lysate/NPs). The reaction was incubated at $37^{\circ} \mathrm{C}$ for $150 \mathrm{~min}$. We used native Cyt $\mathrm{c}$ and untreated cells (lysate only) as a control experiment under the same conditions. Afterward, the Caspase 3/7 assay was performed following the manufacturer's protocol (Ampilite ${ }^{\mathrm{TM}}$ Colorimetric Caspase 3/7 Assay; AAT Bioquest, Sunnyvale, CA, USA). In a 96-well plate, $100 \mu \mathrm{L}$ of the active lysate was mixed with $100 \mu \mathrm{L}$ of the Caspase $3 / 7$ working reagent. Then, the plate was incubated at room temperature for $1 \mathrm{~h}$, and the absorbance was measured at $490 \mathrm{~nm}$ using a Synergy H1 (BioTek, Winooski, VT, USA). The mean \pm SD of the cell-free caspase $3 / 7$ activity was obtained from two independent experiments performed in triplicate. The results were analyzed statistically using the unpaired Student's $t$-test by GraphPad Prism 9.1.1 $\left.{ }^{* * * *} p<0.0001, n=6\right)$.

\subsection{Cell Viability Assay}

MTS cell viability assay (CellTiter 96 aqueous non-radioactive assay) from Promega (Madison, WI, USA) was used to measure the half-maximal inhibitory concentration ( $\left.\mathrm{IC}_{50}\right)$ value for the crosslinked Cyt c-PEG-FA NPs in LLC cancer cells. Lewis lung carcinoma (LLC) cells (10,000 cells/well) were seeded in a 96-well plate and incubated with serial dilutions $(300,200,100,50,25$, and $12.5 \mu \mathrm{g} / \mathrm{mL}$ ) of crosslinked Cyt c-PEG-FA NPs for $24 \mathrm{~h}$ at $37^{\circ} \mathrm{C}$. Controls, such as $300 \mu \mathrm{g} / \mathrm{mL}$ native Cyt c, FA-PEG-NHS, and folate-free Cyt c-DSP 
NPs, were also tested. As a control experiment, FR-negative mouse embryonic fibroblasts (NIH/3T3) cells and FR-positive human cervical carcinoma (HeLa) cells (10,000 cells/well) were also incubated with $300 \mu \mathrm{g} / \mathrm{mL}$ of crosslinked Cyt c-PEG-FA NPs for $24 \mathrm{~h}$. MTS assay was performed following instructions from the kit manufacturer, and the absorbance was measured at $490 \mathrm{~nm}$ using a microplate reader (Tecan Infinite 200 Pro, Meilen, Zurich, Switzerland). The $\mathrm{IC}_{50}$ value was calculated using GraphPad Prism from the dose-response curve: $X=\log (X)$ against the normalized $Y$ (values being $0 \%$ for the smallest value in the data set and $100 \%$ for the highest value data set). The normalized percent of cell viability was plotted against the following log concentrations of crosslinked Cyt c-PEG-FA NPs after $24 \mathrm{~h}: 1.097,1.398,1.699,2.00,2.301$, and $2.477 \mu \mathrm{M}$. Results were expressed as mean values of independent experiments performed in triplicate $(n=9) \pm$ SD. To test the ability of folate to help reduce cancer cell viability, we compared folate-targeted Cyt c NPs and folate-free Cyt c NPs MTS results using an unpaired Student's $t$-test analysis (GraphPad Prism 9.1.1). A difference between folate-targeted Cyt c NPs and folate-free Cyt c NPs cell viability at $300 \mu \mathrm{g} / \mathrm{mL}$ was found, resulting in a statistically significant difference with a $* * * * p$-value of $<0.0001$.

\subsection{In Vitro Cellular Internalization and Endosomal Escape of Cross-Linked Cyt c-PEG-FA NPs}

The crosslinked Cyt c-PEG-FA NP cellular internalization and release into the cytoplasm was observed by confocal laser scanning microscopy (CLSM) in vitro. LLC and $\mathrm{NIH} / 3 \mathrm{~T} 3$ cells $(10,000$ cells/well) were seeded in chambered cover glass plates (with 4 wells). For these experiments, crosslinked Cyt c-PEG-FA NPs were modified by attachment of a fluorescein isothiocyanate (FITC) molecule ( $495 \mathrm{~nm}$ excitation wavelength) in the protein's amino group. Briefly, $25 \mu \mathrm{L}$ FITC $(1 \mathrm{mg} / \mathrm{mL})$ was added to $1 \mathrm{~mL}$ of NP sample $(3 \mathrm{mg} / \mathrm{mL}$ ) dissolved in PBS (pH 7.4) buffer. The reaction of NPs and FITC was stirred at $4{ }^{\circ} \mathrm{C}$ overnight $(\sim 16 \mathrm{~h})$ and covered to block out light and minimize fluorophore quenching. The FITC-labeled NPs were further lyophilized and dissolved in cell culture media at the time of use.

Cell lines were grown at $37{ }^{\circ} \mathrm{C}$ in $5 \% \mathrm{CO}_{2}$ for $24 \mathrm{~h}$ with both: FITC-labeled NPs $(100 \mu \mathrm{g} / \mathrm{mL})$ and the endosome marker FM-464 $(10 \mu \mathrm{g} / \mathrm{mL})$. Afterward, the medium was removed, and the cells were washed with PBS three times, followed by fixation with $3.7 \%$ formaldehyde. After fixation, cells were incubated with DNA fluorescent stain DAPI (358 $\mathrm{nm}$ excitation wavelength) at $1 \mu \mathrm{g} / \mathrm{mL}$ in PBS for $5 \mathrm{~min}$, followed by three washes with PBS alone. For cell imaging, 90\% glycerol in PBS was used as mounting medium. Untreated cells were used as control. For cellular internalization and endosomal escape analysis, the chambered cover glass plates were examined under a Nikon Eclipse Ti-E inverted confocal scanning microscope (Nikon Instruments Inc., Melville, NY, USA) using a $40 \times$ oil immersion objective and excitation at $488 \mathrm{~nm}$. Quantification of the FITC fluorescence intensity of NPs in the red-stained cell membrane area was determined using the NISElement AR analysis program. The difference between the intensities of NP-treated cells, and untreated cells $(p<0.05)$ was used to subtract the green background autofluorescence. Unpaired $t$-test analyses were performed using GraphPad Prism software.

\subsection{Study of Cell Death Induction by Confocal Laser Scanning Microscopy (CLSM)}

LLC cells and NIH/3T3 cells (10,000 cells/well) were seeded on 4-well chambered cover glass plates. The cells were treated with $100 \mu \mathrm{g} / \mathrm{mL}$ of cross-liked Cyt c-PEG-FA NPs at $37^{\circ} \mathrm{C}$ for $24 \mathrm{~h}$. To detect apoptosis and nuclear fragmentation in cells, these were washed with PBS $(1 \times)$ and incubated with the apoptotic cell marker propidium iodide $(75 \mu \mathrm{M})$ for 5 min. Cells were fixed with $3.7 \%$ formaldehyde and incubated with DAPI nuclear stain, followed by three cycles of PBS washing. As a mounting medium, $90 \%$ glycerol in PBS was used. The chambered cover glass plates were examined under a Nikon Eclipse Ti-E inverted confocal scanning microscope (Nikon Instruments Inc., Melville, NY, USA) using a $40 \times$ oil immersion objective. Untreated cells were subjected to DAPI/PI incubation and used as a control. 


\subsection{Study of the Apoptotic Induction Mechanism by Caspase 3/7 Green Detection}

LLC cells (10,000 cells/well) were seeded in 4-well chambered cover glass plates. The cells were incubated at $37^{\circ} \mathrm{C}$ for $24 \mathrm{~h}$ with $100 \mu \mathrm{g} / \mathrm{mL}$ of cross-liked Cyt c-PEG-FA NPs. The activity of caspase $3 / 7$ was determined with the CellEvent ${ }^{\mathrm{TM}}$ caspase $3 / 7$ green reagent (Invitrogen) according to the manufacturer's instructions. The chambered cover glass plates were examined under a Nikon Eclipse Ti-E inverted confocal scanning microscope (Nikon Instruments Inc., Melville, NY, USA) using a 40× oil immersion objective. Untreated cells were subjected to DAPI/CellEvent ${ }^{\mathrm{TM}}$ incubation as well and used as a control. The mean green intensity of the confocal images was measured using the NIS-Element AR analysis program. Unpaired $t$-test analysis by GraphPad Prism comparing NPs-treated cells and untreated cells was considered statistically significant within the 95\% confidence interval $(p<0.05)$.

\subsection{Studies to Detect NPs Organ Distribution}

Our in vivo studies had two different purposes: (1) to test the in vivo tumor-targeting capacity of our new NP system, and (2) to test the efficacy of the NPs in tumor growth. We answered the first question following our previous methodology from Barcelo-Bovea et al. (2020), where we observed NP binding through the different organs at different time points. However, the strongest infrared signal was $5 \mathrm{~min}$ after intravenous injection and was almost undetectable after $1 \mathrm{~h}$. Studies have shown that folate receptor uptake can be as fast as $30 \mathrm{~min}$ or less in cancer cells [34]. Because the diameter of the studied NPs was $169 \mathrm{~nm}$, which is $85 \mathrm{~nm}$ smaller than our previous prototypes, we expected their kinetics to be faster and used the short-time observation window of 5 min to determine whether the nanoparticles reached the tumor target. We chose the intravenous route for these experiments because there is no absorption limitation 'barrier'; it has a fast onset of action, and is clinically applicable. Nevertheless, it is a challenging technique, especially for repeated administrations, and it has a limited volume application (less than $100 \mu \mathrm{L}$ in mice).

To test tumor and organ targeting by NPs after entering the blood circulation, we used a syngeneic (immune-competent) C57BL6J mouse model called Lewis lung carcinoma (LLC). We used 14-week-old mice (C57BL6J wild type strain, male, from Jackson Labs, Bar Harbor, ME, USA) of $25 \mathrm{~g}$ in weight. To develop the Lewis lung carcinoma in these mice, we first grew the LLC murine lung carcinoma cells (commercially obtained, derived from a C57BL6J mouse lung tumor) in a flask, and, after confluency, cells were quantified and injected subcutaneously. LLC mouse cancer cells were cultured in high-glucose Dulbecco's modified Eagle's medium (DMEM) supplemented with 10\% fetal bovine serum (FBS) and $1 \%$ penicillin/streptomycin/amphotericin (PSA) to confluency. Cells were gently removed from the culture flask using a cell scraper, centrifuged at $1500 \times g(5 \mathrm{~min})$, and quantified. After quantification, $1 \times 10^{7}$ LLC cells were obtained and added to a $1.5 \mathrm{~mL}$ tube to a total volume of $200 \mu \mathrm{L}$ with cell media. This $200 \mu \mathrm{L}$ of $1 \times 10^{7}$ cells was added to $200 \mu \mathrm{L}$ of extracellular matrix (ECM) growth factor reduced gel from Engelbreth-HolmSwarm murine sarcoma (Sigma-Aldrich, St. Louis, MO, USA), and they were gently mixed by pipetting. This total of $400 \mu \mathrm{L}$ cells plus ECM was subcutaneously injected into the upper-right dorsal area of the mouse body using a 26 gauge needle to induce tumor growth

Mouse tumors were grown up to $15 \mathrm{~d}$ after implant. These mice were injected by tail vein route with infrared-labeled NPs (IRDye 680RD-labeled NPs) to visualize these. An amount of $0.15 \mathrm{mg}$ of NPs was administered in a volume of $200 \mu \mathrm{L}$, following the protocol of Barcelo-Bovea et al. (2020) [30]. Five minutes after tail vein injection, mice were subsequently euthanized. Tumor and organs (brain, heart, lungs, spleen, kidneys, liver, and intestines) were quickly extracted and scanned for IR-labeled NP distribution using the LI-COR Odyssey CLx infrared scanner. For the tumors, a $42 \mu \mathrm{m}$ resolution and high-quality setting were chosen in Image Studio ${ }^{\mathrm{TM}}$ software (Lincoln, NE, USA). For the organs, a $337 \mu \mathrm{m}$ resolution was used. All the scanned tissue area in the 2-dimensional image was selected for quantification, and the IR signal was scanned and analyzed using 
Image Studio ${ }^{\mathrm{TM}}$. The percentage increase in infrared signal from the control mouse at $5 \mathrm{~min}$ after tail vein injection was calculated following Barcelo-Bovea et al. (2020).

All necessary approvals from the Institutional Animal Care and Use Committee (IACUC) were in place for the performed research: Assurance ID number D16-00343; IACUC Protocol Universal Number 048-2021-08-01-PHA-IBC.

\subsection{Studies to Determine NPS Tumor Decrease in Mice}

Given the efficiency of NPs targeting the tumor tissue, we tested their efficiency in decreasing tumors in mice using the Lewis lung carcinoma (LLC) mouse model. Adult mice ranging from 36 to 60 weeks old, representing an age from adulthood to the reproductive senescence period, were selected for our studies. These mice were implanted with cells to grow a tumor for a total of 12 days. Mice were injected intraperitoneally with $7 \mathrm{mg} / \mathrm{kg}$ Cyt c nanoparticles of $169 \mathrm{~nm}$ at day 3, as an early-tumor stage intervention, and at day 8 , as a late-stage intervention in tumor growth.

Tumor volume was measured manually by caliper every 3 days using the length and width of the tumors:

$$
\text { Tumor volume }=\frac{\text { Tumor length } \times(\text { Tumor weigth })^{2}}{2}
$$

The percentage of tumor growth from day 3 and day 12 (last day) was calculated using the following formula:

$$
\text { Tumor growth }=\left(\frac{\text { Volume at day } 12-\text { Volume at day } 3}{\text { Volume at day } 12}\right) \times 100
$$

A total of $n=6$ mice were untreated, and $n=7$ mice were treated with NPs. An unpaired $t$-test with a Kolmogorov-Smirnov analysis by GraphPad Prism between NP-treated and untreated mice was considered statistically significant within the $95 \%$ confidence interval at $p=0.0385$. Animal weight was also measured to monitor drug safety, as a sharp decrease in body weight (more than 15-20\% during the experiment) is considered unhealthy in tumor models [35]. No difference in mouse weight between groups was observed.

\section{Results}

\subsection{Synthesis and Characterization of Cross-Linked Cyt c-PEG-FA Nanoparticles}

After nanoprecipitation, the diameter of the crosslinked Cyt c NPs was $164 \pm 5 \mathrm{~nm}$, and Cyt c-PEG-FA NPs was $169 \pm 9 \mathrm{~nm}$ (Table 1) as determined by dynamic light scattering (DLS). The NPs generated here were smaller compared to the core-shell Cyt c delivery systems previously developed by our group. The decrease in the zeta potential of the crosslinked Cyt c-PEG-FA NPs $(17.7 \pm 1.7 \mathrm{mV})$ compared with the Cyt c-DSP NPs $(27.5 \pm 3.9 \mathrm{mV})$ confirmed the successful attachment of the FA-PEG-NHS targeting polymer to the amino groups of Cyt c, leading to a reduction in the number of positive charges on the NPs' surfaces.

Table 1. Size, polydispersity index, zeta potential, and precipitation efficiency of different NPs prepared by the nanoprecipitation method.

\begin{tabular}{ccccc}
\hline NPs & Diameter (nm) & $\begin{array}{c}\text { Polydispersity Index } \\
\text { (PDI) }\end{array}$ & Zeta Potential (mV) & $\begin{array}{c}\text { Precipitation } \\
\text { Efficiency (\%) }\end{array}$ \\
\hline $\begin{array}{c}\text { Actual Loading (\%) } \\
\text { Cyt c-DSP NPs }\end{array}$ & $164 \pm 5$ & $0.06 \pm 0.01$ & $27.5 \pm 3.9$ & $96 \pm 2$ \\
Cross-linked Cyt c-PEG-FA NPs & $169 \pm 9$ & $0.09 \pm 0.01$ & $17.7 \pm 1.7$ & $97 \pm 3$ \\
\hline
\end{tabular}

Table data show the averages of three batches of NPs prepared and the respective standard deviations.

Scanning electron microscopy (SEM) was performed to examine the shape of the NPs (Figure 1b,c). The SEM images of lyophilized crosslinked Cyt c NPs and crosslinked Cyt c-PEG-FA NPs showed a spherical shape with a narrow size distribution. 
(a)

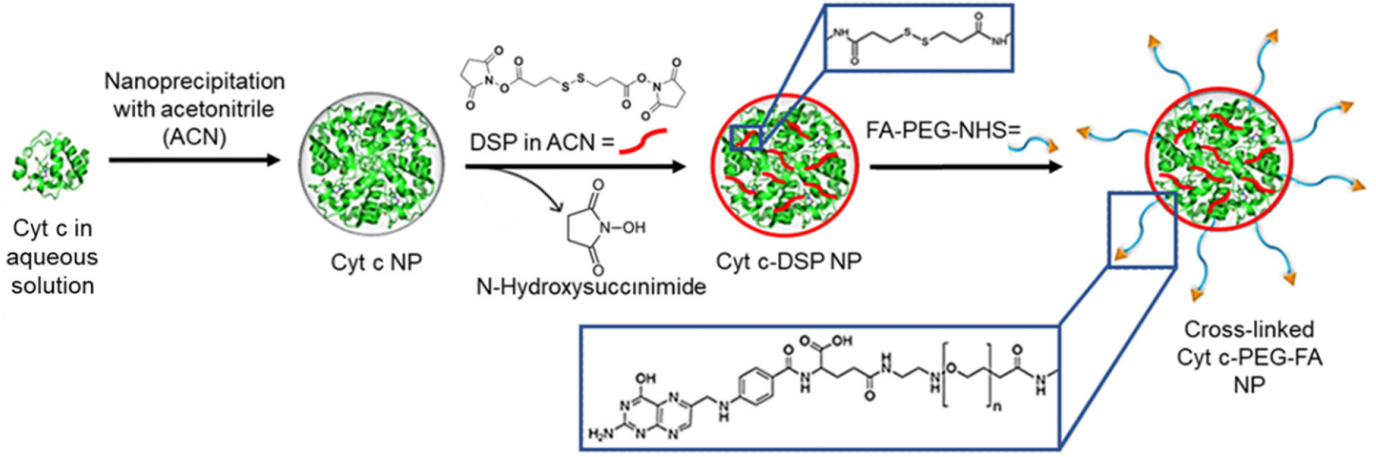

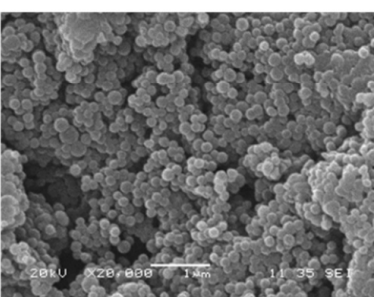

(b)

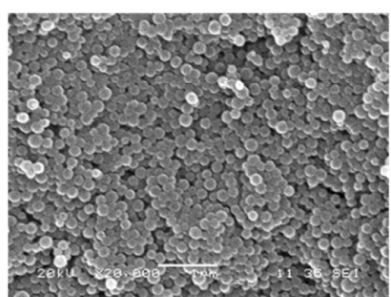

(c) (d)

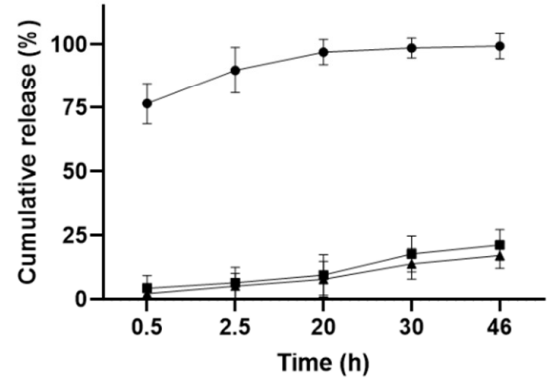

- $10 \mathrm{mM} \mathrm{GSH}$

- $0.001 \mathrm{mM} \mathrm{GSH}$

- $0 \mathrm{mM} \mathrm{GSH}$

Figure 1. (a) Synthesis route of crosslinked Cyt c-PEG-FA NPs. SEM micrographs of (b) crosslinked Cyt c NPs and (c) crosslinked Cyt c-PEG-FA NPs. (d) Cumulative in vitro release profile of Cyt c from crosslinked Cyt c-PEG-FA NPs at $37^{\circ} \mathrm{C}$. NPs were dissolved in PBS buffer with zero GSH (triangles), $0.001 \mathrm{mM} \mathrm{GSH}$ (squares), and $10 \mathrm{mM} \mathrm{GSH}$ (circles) to simulate extracellular (non-reducing) and intracellular (reducing) physiological conditions. Data are the mean \pm SD of experiments performed in triplicate. Statistical analysis by ordinary one-way ANOVA multiple comparison analysis demonstrated a significant difference between the intracellular and extracellular conditions when compared with the control, $p<0.0001$.

\subsection{In Vitro Redox-Responsive Release}

To investigate the cumulative release profile of the crosslinked Cyt c-PEG-FA NPs, we used $10 \mathrm{mM}$ glutathione (GSH) to simulate intracellular conditions, $0.001 \mathrm{mM} \mathrm{GSH}$ to simulate extracellular conditions, and $0 \mathrm{mM} \mathrm{GSH}$ as a control [36]. The cumulative Cyt c release profile is shown in Figure 1d. The crosslinked Cyt c-PEG-FA NPs exhibited an efficient release profile under reducing conditions (10 mM GSH); the most Cyt c was released in the first $0.5 \mathrm{~h}$ as a 'burst release'. In contrast, we found that only about $17 \%$ and $21 \%$ of Cyt c were released using no or $0.001 \mathrm{mM} \mathrm{GSH}$, respectively, and this release was slower than that with $10 \mathrm{mM}$ GSH.

\subsection{Cell-Free Caspase 3 and 7 Assay}

We determined the potential of Cyt $\mathrm{c}$ to interact with Apaf-1 and induce apoptosis after the NP formulation. For this purpose, in vitro cell-free caspase 3/7 activity assays were conducted in a cell-free system (LLC lysate), and native Cyt c was used as a positive control. As shown in Figure 2, the addition of crosslinked Cyt c-PEG-FA NPs to fresh cytosol produced caspase $3 / 7$ activation. Compared to the untreated cells, activation of caspase $3 / 7$ was statistically significantly higher in cells treated with the crosslinked Cyt c-PEG-FA NPs at a $p$-value of $<0.05$ (Figure 2a). Cyt c-PEG-FA NPs had $94 \pm 8 \%$ of their caspase activation activity with no significant difference compared to native Cyt $c$ (Figure 2b). Therefore, since our NPs retained all of their enzyme activity, we demonstrated that the conjugation of the Cyt c NPs does not produce any adverse impact on the capability of the protein to induce apoptosis. 


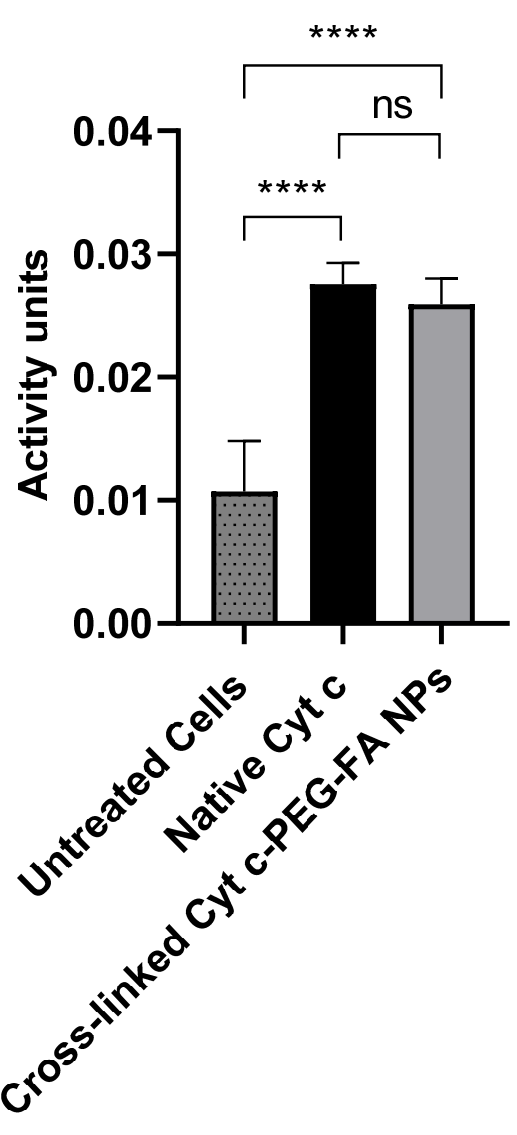

(a)
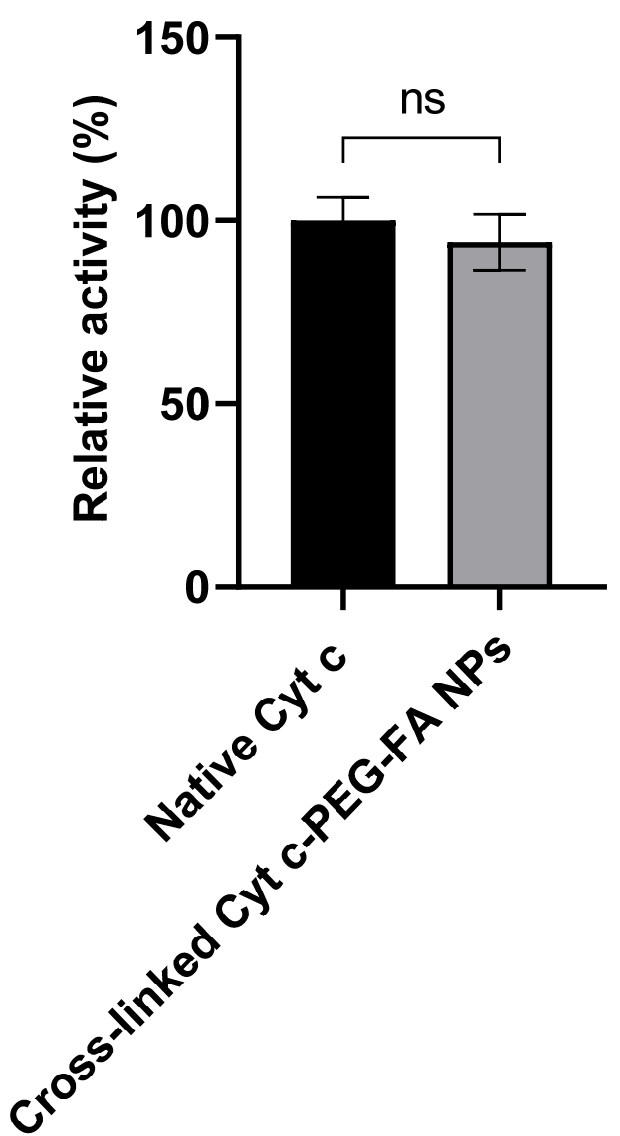

(b)

Figure 2. Activation of caspase $3 / 7$ using a cell-free caspase assay. (a) Compared to untreated cells (control), crosslinked Cyt c-PEG-FA NPs activated caspase 3/7 to a significantly greater extent, similar to the activity provided by the native Cyt c protein. (b) Caspase $3 / 7$ activation of crosslinked Cyt c-PEG-FA NPs compared with the caspase 3/7 activation by native Cyt c. LLC lysate treated with crosslinked Cyt c-PEG-FA NPs was able to activate the caspase $3 / 7$ significantly, similar to that afforded by native Cyt c. The relative caspase activity offered by crosslinked Cyt c-PEG-FA NPs was not significantly different compared to the native Cyt c protein. ${ }^{* * * *}$ Indicates a significant difference $(p<0.0001)$ in an unpaired $t$-test analysis with $n=6$. Error bars represent the calculated SD.

\subsection{Cell Viability Assays}

The cytotoxicity evaluation of crosslinked Cyt c-PEG-FA NPs was performed using an MTS assay. A dose-response graph was constructed upon incubation of FR-positive LLC cells at different concentrations $(12.5,25,50,100,200$, and $300 \mu \mathrm{g} / \mathrm{mL})$ of crosslinked Cyt c-PEG-FA NPs for $24 \mathrm{~h}$. As shown in Figure 3, crosslinked Cyt c-PEG-FA NPs induced a significant reduction in the LLC cell viability in a dose-dependent manner after $24 \mathrm{~h}$ of incubation compared to untreated cells. The calculated $\mathrm{IC}_{50}$ value of the crosslinked Cyt c-PEG-FA NPs was $47.5 \mu \mathrm{g} / \mathrm{mL}\left(\mathrm{R}^{2}=0.9681\right)$. Additionally, the cell viability decreased at increasing concentrations of our NPs. These results demonstrate a clear correlation between the dose concentration of the NPs and its cytotoxic effect. As controls, LLC cells were incubated with native Cyt c, FA-PEG, and Cyt c-DSP NPs (folate-free, the crosslinker alone) at the highest NP concentration $(300 \mu \mathrm{g} / \mathrm{mL})$, as in the corresponding experiment, for $24 \mathrm{~h}$. No significant cytotoxicity was observed after $24 \mathrm{~h}$ with either control compound. For the native Cyt c control, it was expected not to significantly affect the cell viability, since Cyt c is a cell-membrane-impermeable protein. As hypothesized, under the same conditions, folate-conjugated Cyt c NPs significantly reduced the cell viability of folate- 
receptor-expressing LLC cells compared to the folate-free Cyt c NPs $\left({ }^{* * *} p<0.0001, n=9\right.$ ). These results validated the hypothesis that folate-conjugation was required for our NPs to address targetability and induce a cytotoxic potential.

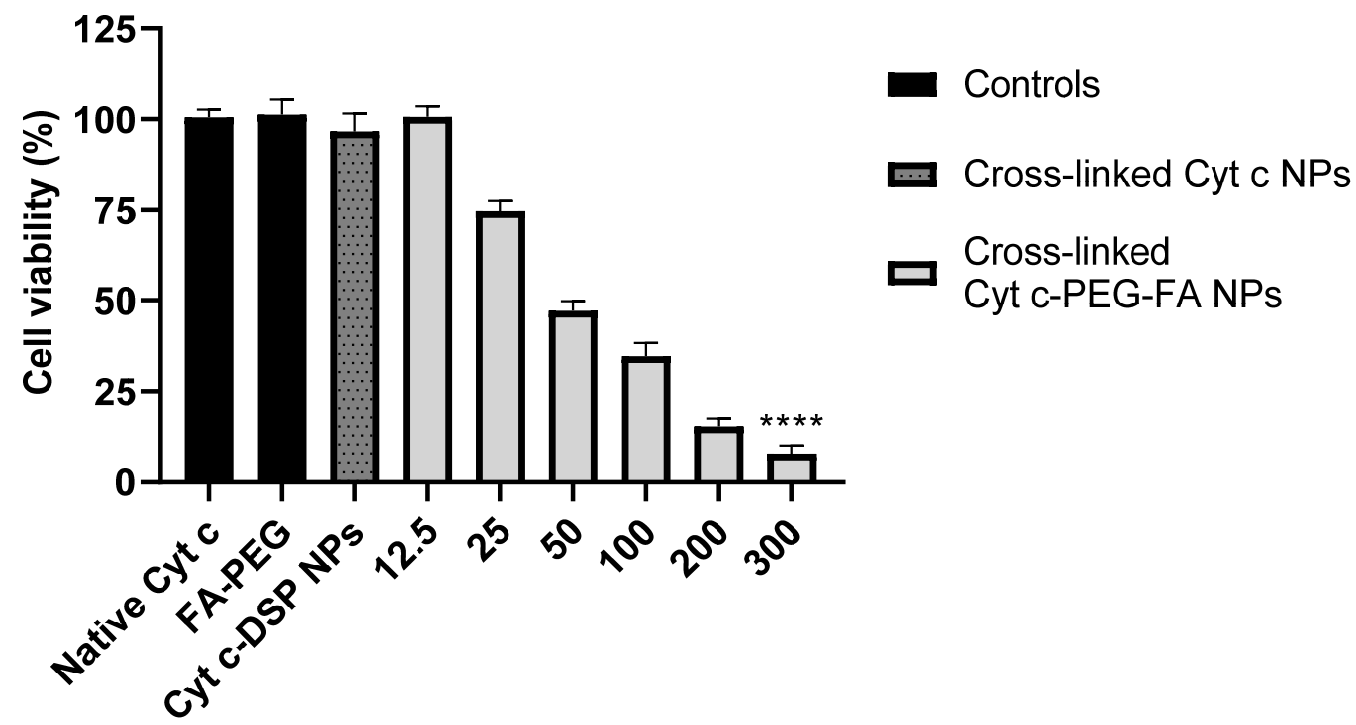

Concentration $(\mu \mathrm{g} / \mathrm{ml})$

Figure 3. MTS cell viability assay of LLC cells after $24 \mathrm{~h}$ of incubation with folate-containing crosslinked Cyt c-PEG-FA NPs in a concentration-dependent manner. The percent of cell viability for the Cyt c-PEG-FA NPs is shown in gray columns, at increasing concentrations from 12.5 to $300 \mu \mathrm{g} / \mathrm{mL}$. This dose-response curve was used to determine the $\mathrm{IC}_{50}$ value of the crosslinked Cyt c-PEG-FA NPs. As controls, we used the native Cyt c (protein alone, no NPs; first black column), PEG-FA (Folate-poly(ethylene glycol)-succinimidyl ester alone; second black column), and Cyt c-DSP NPs (Cyt c with the homo-bifunctional crosslinker DSP, without folate; gray dotted column). All controls were added at a concentration of $(300 \mu \mathrm{g} / \mathrm{mL})$. The cytotoxicities of the folate-free formulation and the folate-bearing NPs at the highest concentration were compared by unpaired $t$-test analysis $\left.{ }^{* * * *} p<0.0001, n=9\right)$. Data shown are expressed as the mean $\pm \mathrm{SD}$.

To evaluate the selective cytotoxic effect of crosslinked Cyt c-PEG-FA NPs for FRpositive cancer cells, we performed a comparative cell viability study with both FR-positive cells (the human cervical carcinoma HeLa cell line and LLC) and FR-negative cells (the mouse embryo fibroblasts NIH-3T3 cell line) [37,38]. As seen in Figure 4, crosslinked Cyt cPEG-FA NPs significantly reduced the cell viability in FR-positive cell lines (LLC and HeLa cells) without a statistically significant difference $(p<0.05, n=9)$. Furthermore, the viability of the NIH/3T3 cells was not significantly affected after $24 \mathrm{~h}$ of incubation with the folateconjugated NPs. These results confirm that our FR-targeted DDS had a significant cytotoxic effect on cancer cells overexpressing FR but not on FR-negative, non-cancerous cells.

\subsection{Study of Apoptotic Mechanism of Cell Death Induction by CLSM}

To confirm whether the cell death was caused by apoptosis, we qualitatively evaluated the occurrence of nuclear segmentation, chromatin condensation, and PI presence in the cell nuclei after their treatment with NPs. LLC cells were treated with crosslinked Cyt c-PEG-FA NPs adjusted to a drug concentration of $100 \mu \mathrm{g} / \mathrm{mL}$. After $24 \mathrm{~h}$ of incubation, the colocalization of DAPI and PI was determined by CLSM. In apoptotic cells, both dyes, PI (red) and DAPI (blue) localized in the nucleus due to the presence of pores in the cell membrane. The nuclei of the permeable LLC apoptotic cells were seen as a bright purple spot in the confocal images due to the colocalization of PI and DAPI (Figure 5). PI internalization is representative of highly condensed and fragmented chromatin in apoptotic cells. Thus, the red fluorescence of PI observed in the nucleus of LLC cells with 
crosslinked Cyt c-PEG-FA NPs confirmed that apoptosis cell death was occurring. In contrast, untreated LLC cells presented no indication of apoptosis, as could be observed by the lack of PI internalization due to the absence of red fluorescence in the confocal images. To evaluate the selectivity of our folate-decorated NPs, we compared the apoptotic cell death of FR-negative NIH/3T3 cells under the same conditions. Confocal images showed a lack of intense PI red fluorescence in the nuclei of NIH/3T3 cells treated with crosslinked Cyt c-PEG-FA NPs, whereas an enhanced red fluorescence in LLC cells was observed. These results are consistent with the intracellular assay and in vitro cell viability results described above, indicating that crosslinked Cyt c-PEG-FA NPs had a significant cytotoxic effect on cancer cells overexpressing FR but not on normal cells.

\subsection{Caspase 3/7 Activity}

Cyt c-mediated apoptosis of a cell involves the activation of caspase 3/7. Exposure of LLC cells to NPs for $24 \mathrm{~h}$ presented a green fluorescence signal induced by the generated caspase $3 / 7$ activity, while the untreated control cells showed a significantly lower fluorescence signal, as was observed by confocal imaging (Figure 6a). A quantitative analysis of these images (in the $488 \mathrm{~nm}$ Ex. channel shown in green) revealed a significant difference $\left({ }^{* *} p=0.003\right.$ ) between non-treated and NP-treated LLC cells (Figure 6b). These results are consistent with the cell-free caspase assay results described in Figure 2, indicating that the crosslinked Cyt c-PEG-FA NPs can substantially increase the apoptosis cell death by cellular events and molecular pathways of caspase regulation.

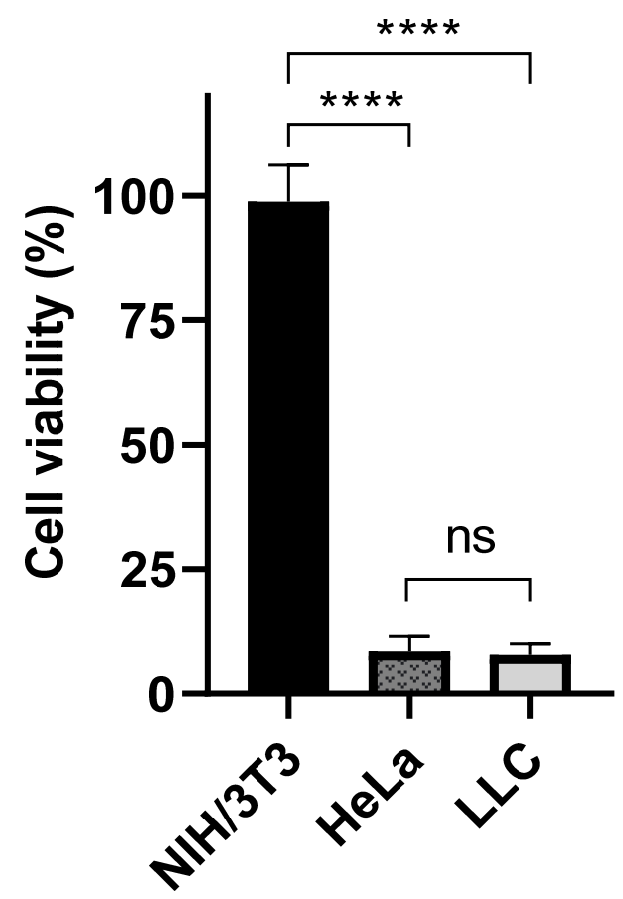

\section{Cell line}

Figure 4. Comparison of the cytotoxicities of crosslinked Cyt c-PEG-FA NPs in cancerous and non-cancerous cell lines. Cell viability MTS assay after $24 \mathrm{~h}$ of NPs treatment at $100 \mu \mathrm{g} / \mathrm{mL}$ using FR-positive cells (LLC and HeLa cells) and FR-negative cells (NIH/3T3 cells). The mean \pm SD was obtained from three independent experiments performed in triplicate. The results were analyzed statistically using an unpaired $t$-test $\left({ }^{* * *}, p<0.0001, n=9\right)$. 
(a) Untreated LLC Cells

(b) NP-treated LLC Cells

(c) Untreated $\mathrm{NIH} / 3 \mathrm{~T} 3$

Cells

DAPI

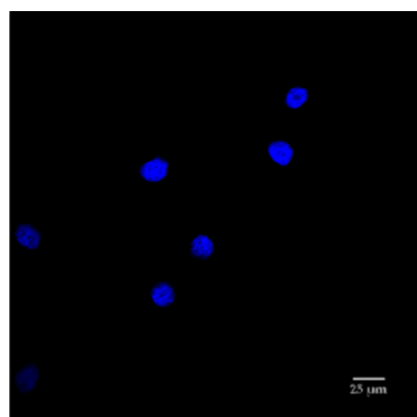

PI
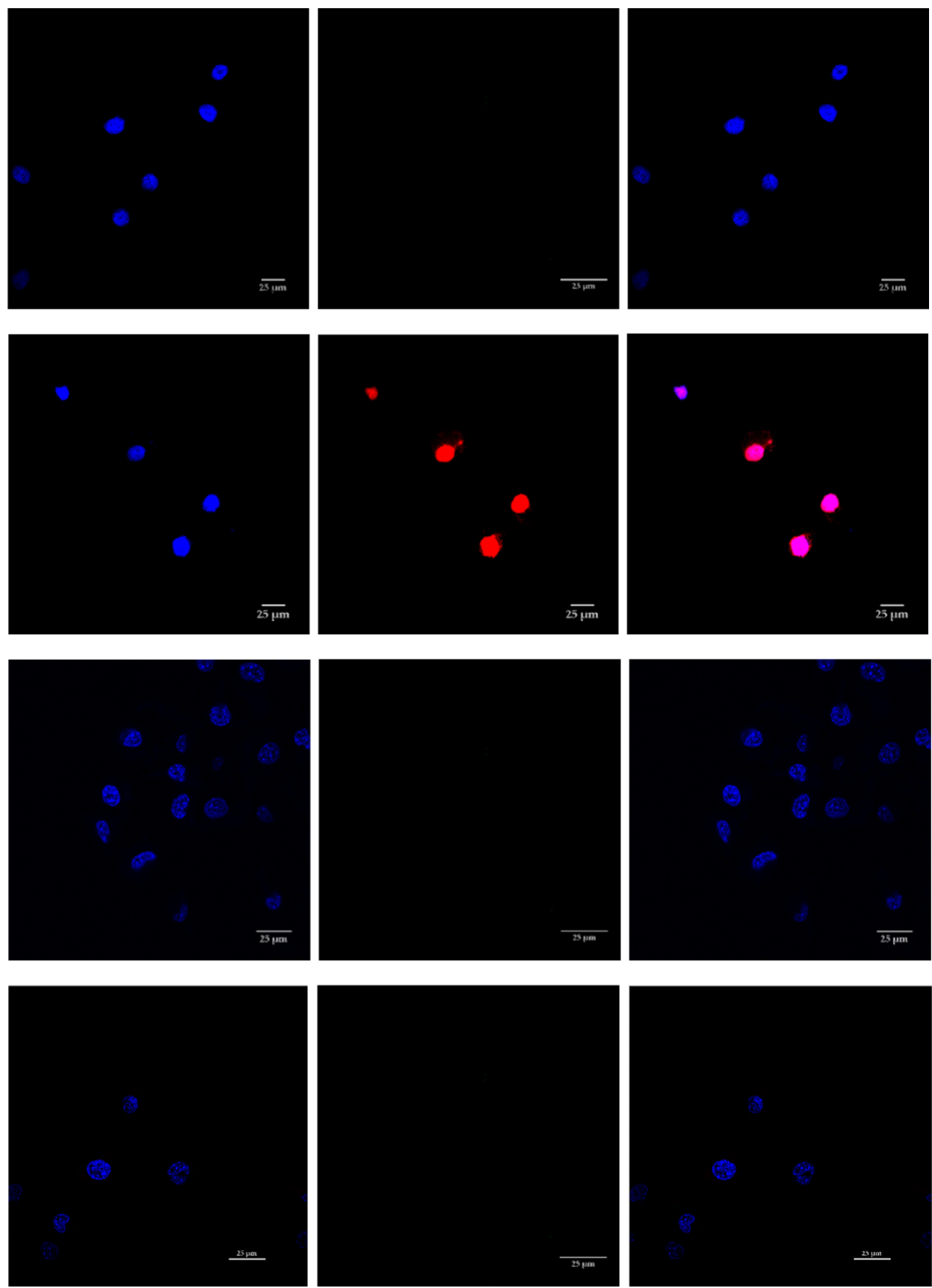

Figure 5. Study of DAPI and propidium iodide (PI) colocalization for the detection of apoptotic cells after $24 \mathrm{~h}$ of incubation with crosslinked Cyt c-PEG-FA NPs. (b) Selective induction of apoptosis was observed in LLC cells incubated with NPs. (c) No cellular apoptosis was observed in NIH/3T3 cells when incubated with NPs. (a,d) Untreated LLC and NIH/3T3 cells were used as controls, respectively. 


\section{Untreated Cells NP-treated Cells}

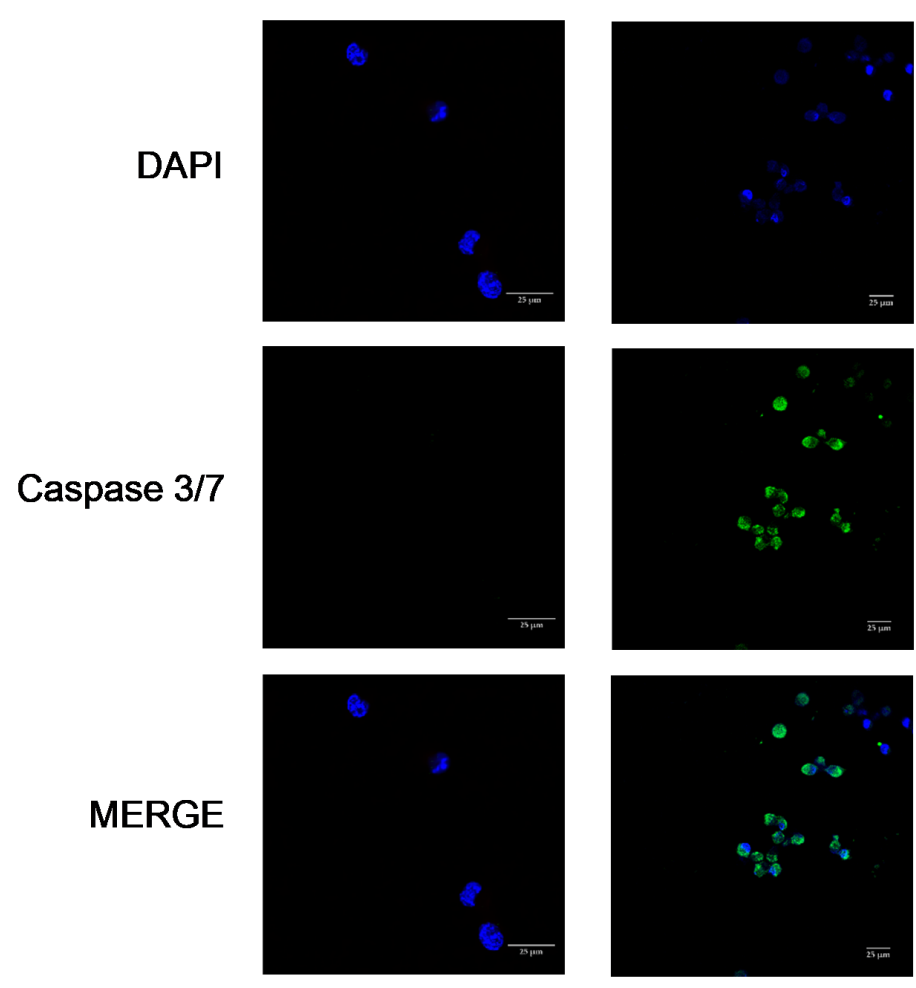

(a)

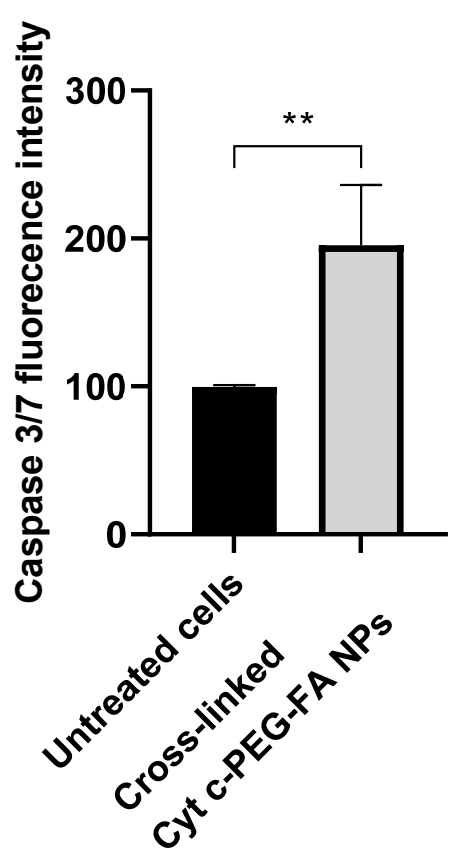

(b)

Figure 6. Caspase $3 / 7$ activation in LLC cells after $24 \mathrm{~h}$ of incubation with $100 \mu \mathrm{g} / \mathrm{mL}$ of crosslinked Cyt c-PEG-FA NPs. The caspase $3 / 7$ activity was assayed by CellEvent ${ }^{\mathrm{TM}}$ caspase $3 / 7$ fluorescent green detection reagent and measured by CLSM. (a) The left panel shows untreated LLC cells used as a negative control to establish the green autofluorescence background, and the right panel shows LLC cells treated with the NPs. Scale bar $=25 \mu \mathrm{m}$. (b) Quantitative analysis of green fluorescence (488 nm Ex.) in untreated versus NP-treated cells. The results are expressed as mean \pm SD and were significantly different $(* * p=0.003$, unpaired $t$-test analysis, $n=3)$. 


\subsection{Cellular Internalization of Cross-Linked Cyt c-PEG-FA NPs}

To investigate the FR-mediated endocytosis mechanism and endosomal escape capability of the crosslinked Cyt c-PEG-FA NPs, FR-positive LLC cells were incubated with FITC-labeled crosslinked Cyt c-PEG-FA NPs and the endosome marker FM-464 for $24 \mathrm{~h}$. The fluorescence intensity of FITC-labeled NPs in LLC cells was observed by Z-stack confocal laser scanning microscopy. The confocal Z-stack images obtained from the endosome marker channel showed red fluorescence, while the images of nuclei stained by the DAPI showed blue fluorescence. The green fluorescence observed in the confocal Z-stack images is caused by the internalization of the FITC-labeled crosslinked Cyt c-PEG-FA NPs (Figure 7). The yellow fluorescence is due to the colocalization of the two dyes and shows NP entrapment in endosomes [39]. The confocal Z-stack images reveal that FITC-labeled NPs were found in the cytoplasm after $24 \mathrm{~h}$. Furthermore, some of the FITC-labeled NPs were still entrapped in endosomes (yellow spots), agreeing with the expected uptake by endocytosis. These results confirm the potential of the crosslinked Cyt c-PEG-FA NPs for tumor-targeted drug delivery.

$1.40 \mu \mathrm{m}$

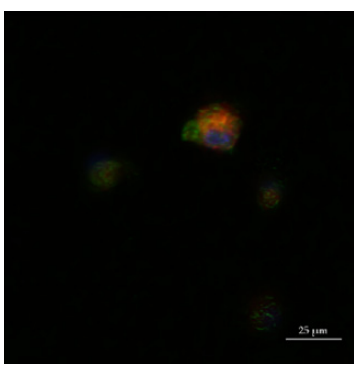

$6.20 \mu \mathrm{m}$

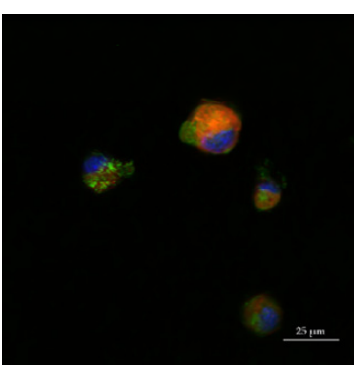

$11.0 \mu \mathrm{m}$

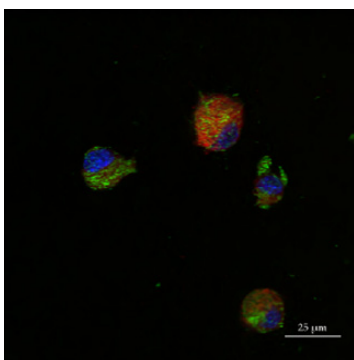

$2.60 \mu \mathrm{m}$

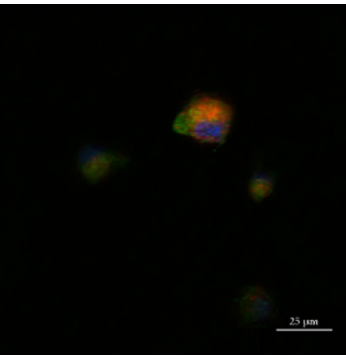

$7.40 \mu \mathrm{m}$

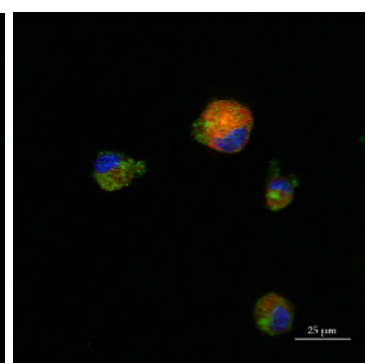

$12.20 \mu \mathrm{m}$

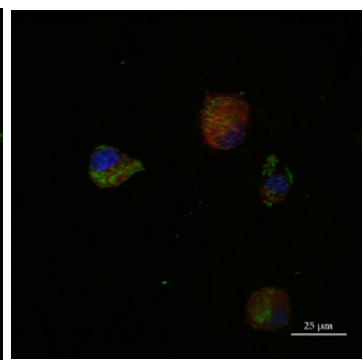

$3.80 \mu \mathrm{m}$

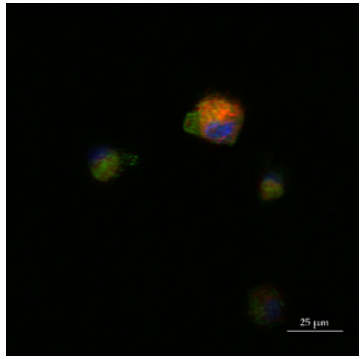

$8.60 \mu \mathrm{m}$

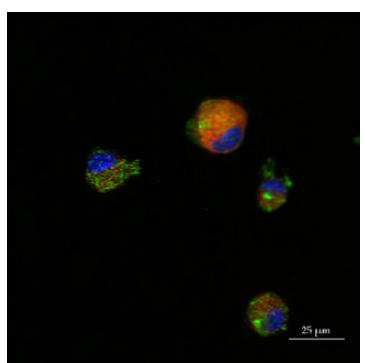

$13.40 \mu \mathrm{m}$

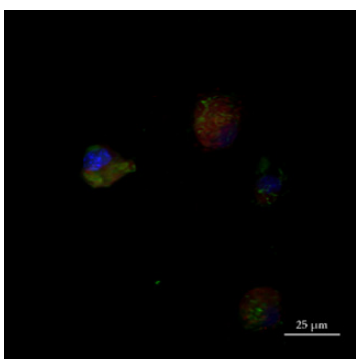

$5.00 \mu \mathrm{m}$

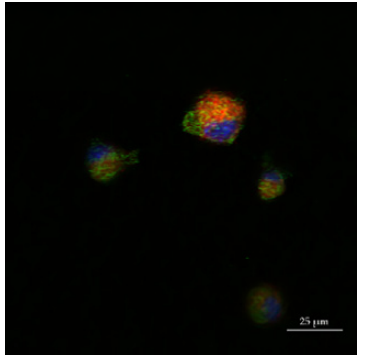

$9.80 \mu \mathrm{m}$

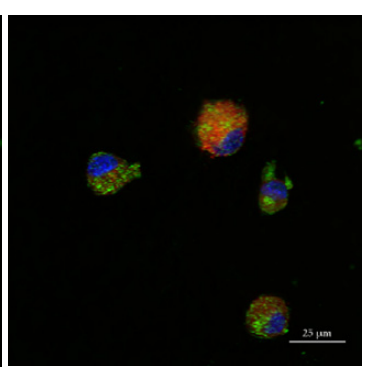

$14.60 \mu \mathrm{m}$

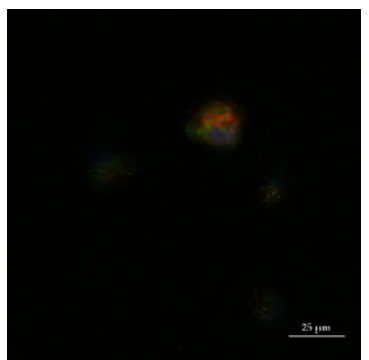

Figure 7. Endosomal colocalization of Cyt c-PEG-FA NPs in LLC cells using Z-stack confocal imaging. LLC cells were incubated with FITC-labeled NPs (green fluorescence) at $100 \mu \mathrm{g} / \mathrm{mL}$ concentration and FM-464 endosome marker (red fluorescence) for $24 \mathrm{~h}$. The cell nuclei were stained with DAPI, shown in blue. The yellow color indicates the localization of the NPs in the endosomes. Scale bar $=25 \mu \mathrm{m}$. 
The internalization of crosslinked Cyt c-PEG-FA NPs by non-cancer NIH/3T3 cells was also tested to confirm the specificity of our NPs to cells overexpressing folate receptors by confocal microscopy. For this purpose, FR-positive cells (LLC and Hela cells) were compared with the folate-negative NIH/3T3 cell line. Consistent with the NP uptake experiment described above, a significant amount of green fluorescence from FITC-labeled NPs was located in the cytoplasm of the FR-positive cell lines, and the colocalization with FM-464 (yellow spots) indicates NPs were also present in endosomes (Figure 8). These results indicate that the FITC-labeled NPs escaped from endosomes of the FR-positive cancer cells within $24 \mathrm{~h}$ of endocytosis. However, in FR-negative NIH/3T3 cells, NPs remained mainly accumulated extracellularly, and only weak yellow spots were observed in the micrographs, indicating no overlap between FITC-labeled NPs and endosome markers. These results confirm that the level of folate receptors on the cell surface affected the drug internalization. Because of the undetectable level of FR at the normal NIH/3T3 cell surface, the intracellular uptake of the crosslinked Cyt c-PEG-FA NPs decreased, and the intracellular drug release was reduced, which resulted in minimal uptake.

DAPI
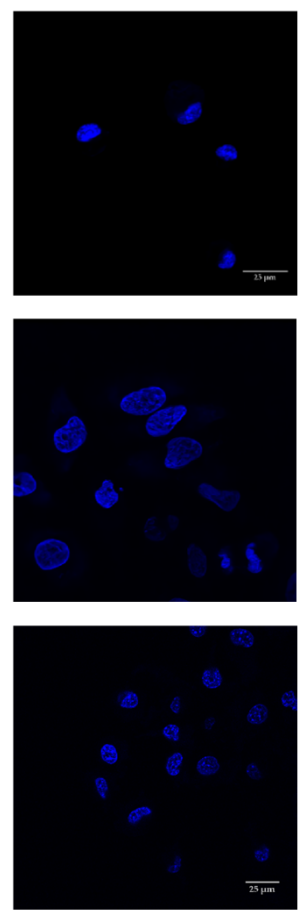

FM-464
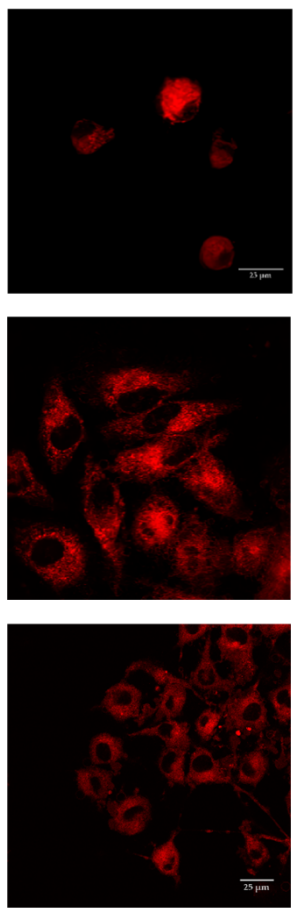

FITC
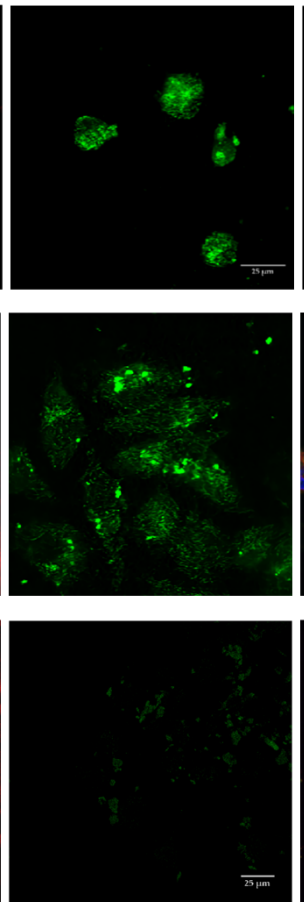

\section{MERGE}
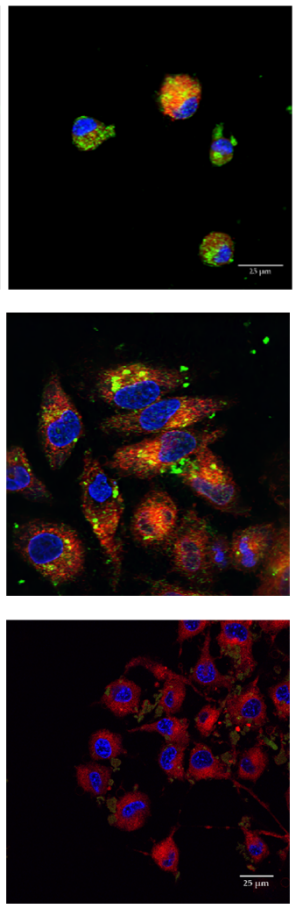

Figure 8. Internalization of FITC-labeled crosslinked Cyt c-PEG-FA NPs by FR-positive cancer LLC and HeLa cells and FR-negative non-cancer NIH/3T3 cells. Confocal images of both cells treated with FITC-labeled crosslinked Cyt c-PEG-FA NPs and endosome marker (FM-464) after a $24 \mathrm{~h}$ incubation. The yellow color in the merged images indicates the localization of the NPs in the endosomes. The nuclear stain DAPI is shown in blue. Scale bar $=25 \mu \mathrm{m}$.

\subsection{Biodistribution of Cross-Linked Cyt c-PEG-FA NPs in Tumor-Bearing Mice}

For the in vivo tracking of the NP distribution, C57BL6J male mice (14-week-old) bearing Lewis lung carcinoma were tail-vein injected with $0.15 \mathrm{mg}$ of NPs labeled with the fluorescent IRDye 680RD (IR-labeled NPs). After 5 min post-injection, tumors and organs (brain, heart, lungs, spleen, kidneys, liver, and intestines) were quickly extracted and scanned using the LI-COR Odyssey CLx infrared scanner. High-resolution images showed an enhanced fluorescence signal (64\%) from the tumor region of the mice injected with IR-labeled NPs compared to the mice injected with PBS, which was used as a negative control to subtract the fluorescence signal from the tumors' autofluorescence (Figure 9). A 
quantitative analysis of fluorescence images of the other tissues, including spleen (98\%), heart $(66 \%)$, and intestines $(293 \%)$, showed organ deposition of a considerable amount of NPs, whereas fluorescence in the liver (24\%) and brain (25\%) was minimally detectable. The fluorescence signal recovered from the tumors and organs was presented as a $\%$ IR signal of NP-injected tissue over the control tissue. Therefore, our results demonstrate a successful tumor accumulation of the crosslinked Cyt c-PEG-FA NPs.

Tumor without NPs

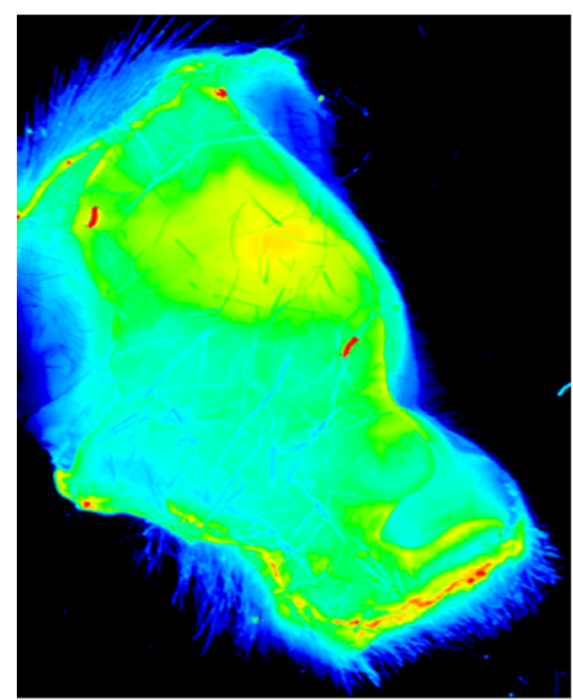

IR-NPs

\section{Tumor with IR-NPs}

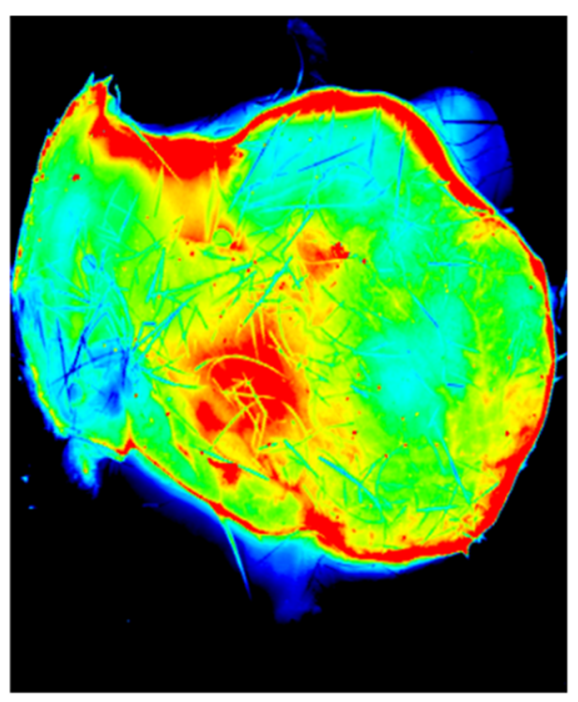

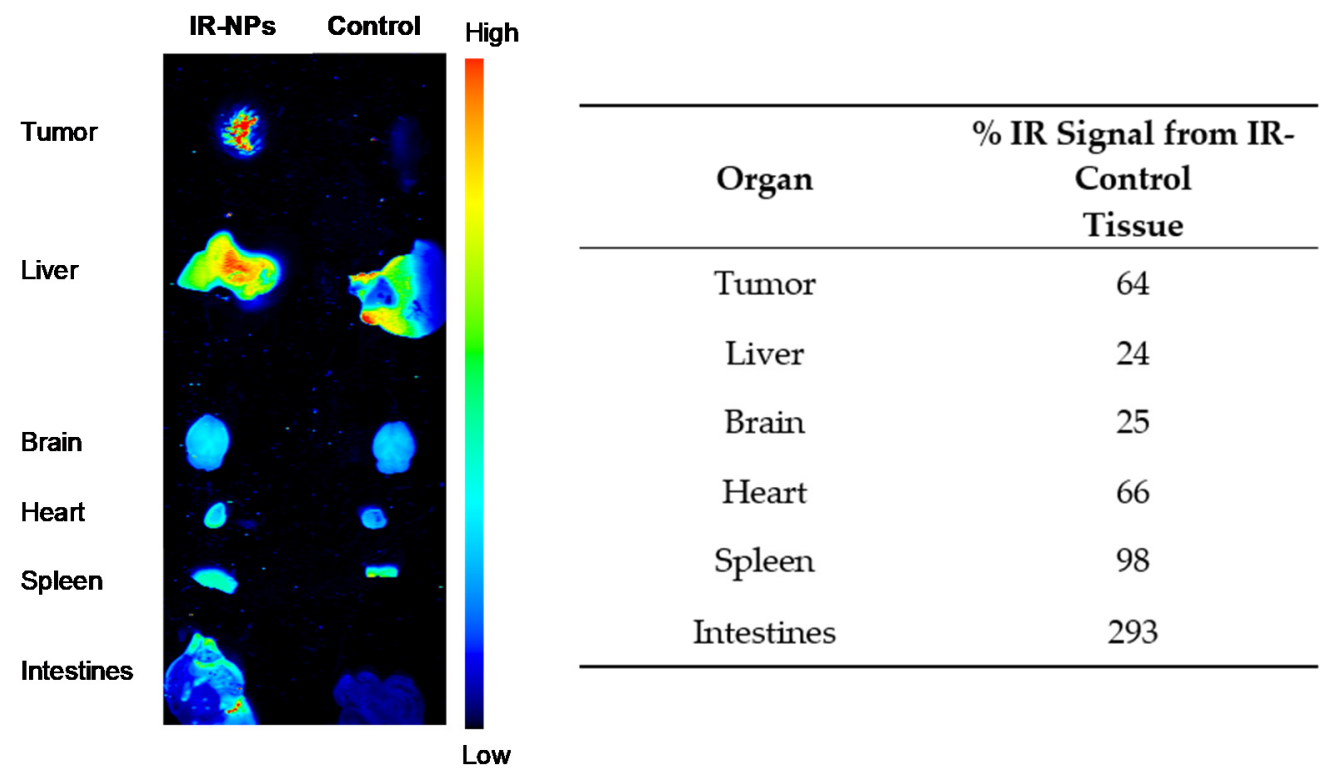

Figure 9. Infrared (IR) signal of organs and tumors after injection of IR-labeled-NPs. Upper panel: A high-resolution image of the ventral sides of tumors shows what appear to be NPs in the NP-injected mouse tumor but not in the control mouse. Lower-left panel: Five minutes after tail vein injection of IR-labeled nanoparticles or no nanoparticles into LLC tumor-bearing mice, tumors and organs were excised and scanned for IR signal at $680 \mathrm{~nm}$ (high intensity in red and low intensity in blue) using an infrared scanner (LI-COR). Lower-right panel: Percentage of IR signal in the organs of an IR-NP-injected mouse after 5 min compared to control.

\subsection{Induction of Lewis Lung Carcinoma in Mice to Assess NP Efficacy on Tumor Growth}

C57BL/6J mice were implanted with LLC cells to each grow a tumor for a total of 12 days. For the NP treatment, mice were injected intraperitoneally with $7 \mathrm{mg} / \mathrm{kg}$ of 
crosslinked Cyt c-PEG-FA NPs (169 nm) at day 3 as an early-stage tumor intervention, and at day 8 , as a late-stage intervention in tumor growth. Figure 10 shows a representative image of the regime used. Tumor volume was measured manually by caliper every 3 days using the length and width of tumors, and the mice's weight was also monitored as a general health measurement. Using an unpaired $t$-test with a Kolmogorov-Smirnov posttest between the NP-treated and untreated mice showed a significant decrease in tumor size in NP-treated mice ( $p=0.0385$, Figure 11a).

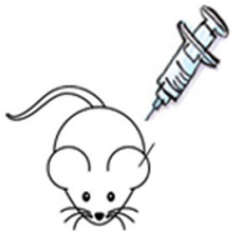

C57BL/6J mice

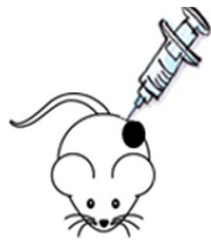

Inject NPs

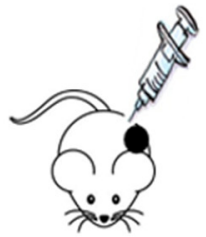

Inject

NPs

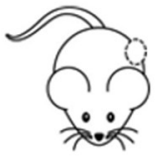

Harvest tumor

\section{Timeline}

Days

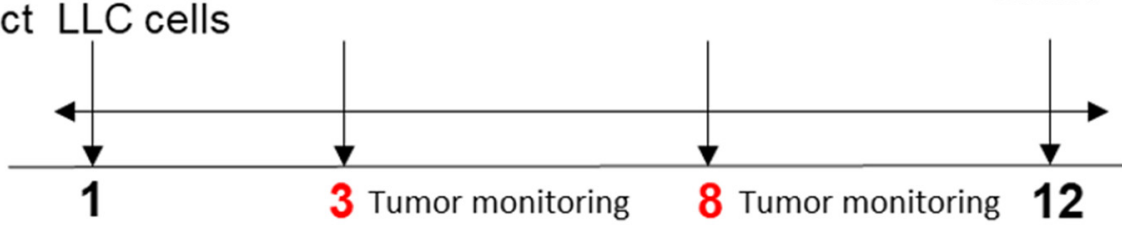

Figure 10. Treatment regime for C57BL/6J mice. Male mice (36-60 weeks) were divided into two groups and treated with 90\% PEG 400/10\% ethanol vehicle (i.p.) or $7 \mathrm{mg} / \mathrm{kg}$ of NPs dissolved in a vehicle (i.p.) at days 3 and 8 after the tumor implant. Tumor monitoring was performed manually by caliper measurement at days 3,6,9, and 12, and weight was monitored as a general health measurement in our mouse model.

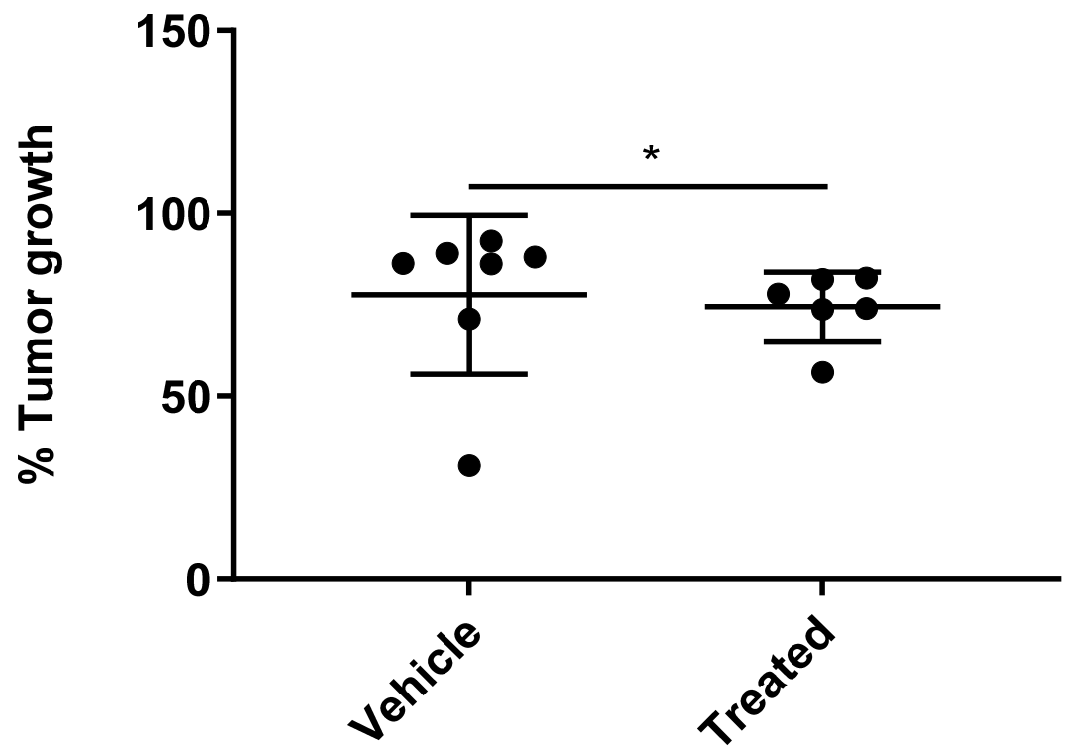

(a)

Figure 11. Cont. 


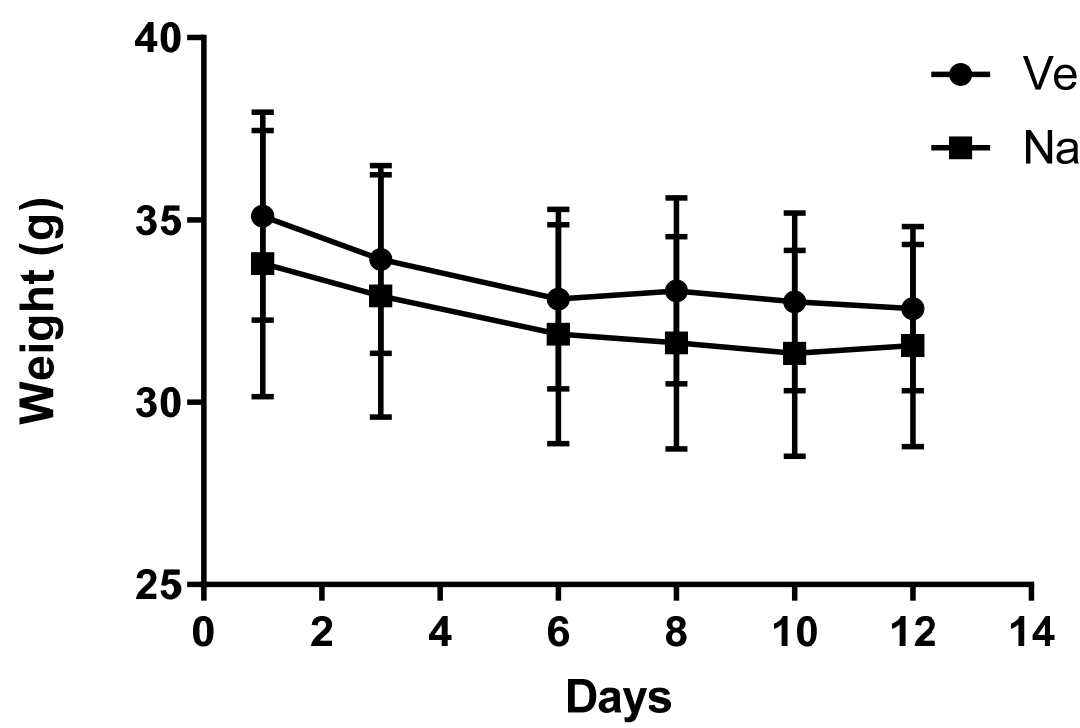

(b)

Figure 11. Percentage of tumor growth and mouse weight in NP-treated and untreated mice. (a) Tumor growth monitoring was performed in male mice manually by caliper measurement. (b) Mouse weight was monitored using a rodent balance. A $t$-test and Kolmogorov-Smirnov post-test on percentage tumor growth showed ${ }^{*} p=0.0385$, while mouse weight was not significantly different between both groups. Vehicle $(n=6)$ and NP-treated $(n=7)$.

Our results show no significant difference in mouse weight between groups (Figure 11b). This underscores the safety and suitability of the crosslinked Cyt c-PEG-FA NPs as a DDS for FR-overexpressing tumor therapy. These results are consistent with the in vitro therapeutic efficiency and the in vivo tumor accumulation of the crosslinked Cyt c-PEG-FA NPs.

\section{Discussions}

Considering the many advantages of protein-based NPs to facilitate their clinical applications and the exemplary success of anticancer NP-based drug formulations, such as Abraxane ${ }^{\circledR}$, our results show a proof-of-concept that crosslinked Cyt c-PEG-FA NPs have the potential to improve tumor-targeting and anti-tumor effects in drug delivery. Our fast infrared NP detection system could be used as a tumor diagnostic agent for folate overexpressing cancers, and further development of the system could have theragnostic potential [40]. Previously, Cyt c NPs stabilized by the hydrophobic polymer poly (lacticco-glycolic) acid (PLGA) demonstrated that these NPs were an efficient method to induce cell death in lung carcinoma cell culture, and bound to the tumor site in the LLC murine model [29]. Recently, we overcame dose limitations previously seen in the PLGA-based NPs for Cyt c by designing smaller Cyt c-based NPs coated with a low-molecular-weight polymer, FA-PEG. In the current study, Cyt c NPs were stabilized using a thiol-cleavable homo-bifunctional crosslinker that incorporates a triggered release mechanism mediated by the reducing environment inside the cancer cells-without the need for PLGA. This NP formulation showed improved cytotoxicity and biocompatibility compared to a previous report [25]. In addition to having an optimal and reduced NP size ( 169 nm, compared to the previous system of $\sim 254 \mathrm{~nm}$ ), this new generation of NPs is more straightforward and economical to prepare, which is critical to the development of accessible anticancer drugs. Reviews of NPs have concluded that after many studies of the sizes, shapes, and surface modifications of NPs, a suitable size for NPs targeting tumors is 100-200 nm. These particles display increased tumor penetration, because they are large enough to avoid being cleared by the kidneys or through vascular extravasation (which eliminates particles of $10-100 \mathrm{~nm})[41,42]$, and they are still large enough to avoid filtration by the kidneys and spleen (300-500 nm) [23]. Our presented NPs of $169 \mathrm{~nm}$ fall within this optimal size. This 
should also improve their passive tumor entry and accumulation due to the enhanced permeability and retention effect (EPR) caused by the unstable tumor vascularization, which leads to a better drug efficacy within the tumor microenvironment [26].

Studies have shown that increasing the flow rate of the solvent and antisolvent during the nanoprecipitation process can cause a considerable reduction in the particle size in nanosuspension [43]. Therefore, in these studies, the nanoprecipitation method was optimized by increasing the flow rate of the solvent-displacement process two-fold, resulting in a diameter of $169 \mathrm{~nm}-$ a $30 \%$ reduction compared to the previous system-and producing a positive NP surface charge $(+17 \mathrm{mV})$. For this system, our strategy was to modify the surface of the Cyt c NP with both a redox-responsive homo-bifunctional crosslinker (DSP) and a lower-molecular-weight polymer (FA-PEG), making it a potential candidate for intravenous (i.v.) administration [3,26]. Whereas the crosslinker shell stabilized the core of the Cyt c-based NP, the polymer provides the surface for FR-overexpressing tumor targeting. The SEM images of the crosslinked Cyt c-PEG-FA NPs showed a spherical shape with narrow size distribution, and confirmed the nanometer range of the NP size determined by DLS. Previous limitations of protein delivery systems, including low protein loading and poor protein stability, also improved with the crosslinker.

The DSP is a cell-membrane-permeable crosslinker with a disulfide bond that can be reduced in the intracellular environment, preventing the disintegration of the NP in an aqueous environment [44]. Our in vitro drug release results show an excellent release of around $90 \%$ of Cyt $\mathrm{c}$ in $2.5 \mathrm{~h}$ under reducing intracellular conditions and high stability under extracellular physiological conditions. However, protein structures can respond to changes in their chemical and physical environment in the NP formulation process [45]. Cyt c's action as an anticancer drug depends on the mitochondrial apoptosis pathway, which is responsible for activating the executioner caspases $3 / 7$ that target various protein substrates, leading to cell disassembly and DNA fragmentation [46]. We demonstrated that the crosslinked Cyt c-PEG-FA NPs retained all their enzyme activity ( $94 \pm 8 \%$ ) through a cell-free caspase 3/7 activation assay, meaning that the integrity of Cyt c after the NPformulation procedure was not compromised. This result is significant, because many of the Cyt c surface lysine residues are known to be involved in the Apaf-1 interaction, which is essential to the mitochondrial apoptosis pathway [47]. Therefore, we demonstrated that our delivery system displayed high stability in physiological conditions and smart-release behavior in a reductive intracellular environment, retaining all its protein bioactivity to interact with the Apaf- 1 and activate the apoptosis pathway.

Conventional chemotherapy limitations arise from a lack of specificity and systemic toxicity without the discrimination of healthy tissues. Therefore, a cell viability study was conducted to investigate the cytotoxic potential of the crosslinked Cyt c-PEG-FA NPs in lung carcinoma cancer cells. We used the Lewis lung carcinoma (LLC) cell line as the lung carcinoma model because it expresses high levels of FRs, is highly tumorigenic, and is primarily used to evaluate the efficacy of chemotherapeutic agents in vivo [48]. For example, the LLC mouse model was a successful in vivo preclinical prototype for assessing the drug called Navelbine ${ }^{\circledR}$ before human testing in clinical trials [49]. Our in vitro cell viability studies demonstrate that the crosslinked Cyt c-PEG-FA NPs were significantly more cytotoxic towards FR-overexpressing cancer cell lines, including human HeLa cancer cells. In contrast, no significant or minimal cytotoxicity was observed in the non-cancerous $\mathrm{NIH} / 3 \mathrm{~T} 3$ cell line. In addition, HeLa cell death induced by the NPs demonstrated the translational application of our system to human FR-overexpressing cancers. Thus, the selective cytotoxic efficacy of the crosslinked Cyt c-PEG-FA NPs in FR-receptor-overexpressing cancer cells over an FR-negative non-cancer cell line was confirmed.

The cellular apoptotic process induced by Cyt $\mathrm{c}$ is one of two apoptotic mechanisms, named 'intrinsic', 'mitochondrial', or 'stress-induced'. In this intrinsic pathway, a sequential protein activation process leads to the release of Cyt $\mathrm{c}$ from the mitochondria, which in turn activates caspases 9,3, and 7, which mediate the mechanisms of organized cellular death [50]. Among these processes, we can observe apoptotic cells displaying their 
characteristic nuclear segmentation and chromatin condensation [51]. For visualization of apoptosis, DAPI and PI colocalization studies have been used to detect apoptotic cells [52]. Our results showed that colocalization of DAPI and PI occurred in LLC cells, indicating ongoing late apoptosis, whereas NIH/3T3 cells showed no indication of dye colocalization. These results demonstrate that the crosslinked Cyt c-PEG-FA NPs induced selective cell death in FR-overexpressing cancer cells without affecting healthy cells, thus confirming these NPs' selectivity regarding cancer cells.

To expand the molecular and cellular mechanism underlying the early apoptotic induction of the NP treatment in LLC cells, we examined fluorescent caspase 3/7 activation in cell cultures using confocal microscopy and a cell-free assay. Both methodologies confirmed that the Cyt c protein carried by our targeted-PEGylated NPs effectively initiated tumor cell apoptosis in cancer cells.

Because our NPs were smaller than $500 \mathrm{~nm}$ and had an FA ligand attached to their surfaces, they could be internalized through receptor-mediated clathrin-enabled endocytosis [53]. This internalization mechanism is initiated after a specific ligand-encased nanomaterial binds to a receptor on the surface of the cell membrane. After $24 \mathrm{~h}$ of LLC cell incubation with our FITC-labeled crosslinked Cyt c-PEG-FA NPs, the amphiphilic dye FM 464 was used as our endosome marker to confirm the uptake of our NPs in FR-positive cells. Our Z-stack confocal microscopy results showed a colocalization of FM 464, with our fluorescently labeled NPs showing a successful uptake.

Further confocal micrograph studies showed a significantly higher intracellular uptake of PEG-FA NPs by FR-positive cancer cells (HeLa cells and LLC) over FR-negative cells (NIH/3T3), indicating that the internalization of these NPs was specific and mediated via an FR-receptor and clathrin-mediated endocytosis mechanism. The internalized FITClabeled NPs were identified inside the cytoplasm and surrounding the nucleus in the FR-overexpressing cell lines. Overall, our endocytosis results suggest that our NPs had an appropriate size, shape, adequate surface charge, and coating to be efficiently internalized by cancerous cells, and could have potential as anticancer nanocarriers [54].

Our in vivo studies demonstrated tumor targeting by showing that, at 5 min after intravenous injection, the NPs were visible within the tumor. At this early time point, most NPs were still present within organs including the intestines, spleen, heart, brain, and liver. From our experience with similar NPs, these would be later metabolized after $6 \mathrm{~h} \mathrm{[29].}$ Nevertheless, further toxicological analyses of the organs at different time points after NP treatment need to be performed to confirm the elimination of this drug.

Our studies determined that the crosslinked Cyt c-PEG-FA NPs were able to reach the tumor, and we further tested the safety and tumor decrease effectivity of these NPs in vivo. Results show that after two doses of NPs at $7 \mathrm{mg} / \mathrm{kg}$, after 12 days, mice showed no significant differences in weight compared with the vehicle group (control); they looked groomed, changes in locomotion were not detected, and they showed no evident signs of toxicity throughout the treatment period. These results suggest that the NPs are safe and have low toxicity, which could make their use for future clinical translation possible. In addition to their safety, our NPs also significantly decreased the percentage of tumor growth consistently by at least 5\%. Future improvement of these NPs' formulation, dosage, and combined therapy could increase the treatment's outcome, but it already shows promising results as the first in vivo proof-of-concept trial. Other FR-targeted DDS loaded with well-known anticancer drugs have shown positive results, decreasing tumor growth in vivo $[55,56]$ and reducing their toxic effects by nanoencapsulation. Our approach serves as a platform for the creation of drug delivery systems employing apoptosis-inducing or other pharmaceutical proteins for various therapeutic applications.

\section{Conclusions}

In the present work, we report the development of a crosslinked Cyt c-PEG-FA NP drug delivery system that was designed for FR-mediated targeting and the intracellular redox-sensitive release of the apoptotic protein Cyt c. Our results indicate that our NPs 
had a significant tumor-growth suppressive effect on cancer cells with FR overexpression in vitro and in vivo. The in vitro results demonstrate that our NPs were adequately sized for tumor targeting, selectively internalized in FR-overexpressing cancer cells, and able to induce apoptosis, activating a caspase 3/7 mechanism without affecting normal cells. Indeed, our results strongly suggest that the size of an NP plays an important role in the cytotoxic effect compared with our previous Cyt c-based delivery system stabilized by PLGA. Our in vivo studies using an immune-competent mouse model of lung carcinoma demonstrated tumor targeting by showing that at 5 min after intravenous injection, the NPs were visible within the tumor. In the same mouse model, our NPs effectively suppressed tumor growth, most probably through the apoptotic activation of caspase 3/7 in tumor cells, without notable side effects. Therefore, these results showcase the potential of our crosslinked Cyt c-based NPs for targeted anticancer therapeutics, avoiding problems associated with many of the common cytotoxic anticancer agents, such as their unspecific targeting of healthy cells and drug resistance.

Author Contributions: Conceptualization, I.D.-M., Y.F.-A. and K.H.G.; methodology, I.D.-M., Y.F.-A. and K.H.G.; validation, I.D.-M., Y.F.-A. and K.H.G.; formal analysis, I.D.-M. and Y.F.-A.; investigation, I.D.-M., F.J.-O. and Y.F.-A.; resources, Y.F.-A. and K.H.G.; data curation, I.D.-M. and Y.F.-A.; writingoriginal draft preparation, I.D.-M., Y.F.-A. and K.H.G.; writing-review and editing, I.D.-M., Y.F.-A. and K.H.G.; visualization, I.D.-M. and Y.F.-A.; supervision, K.H.G., Y.F.-A. and I.D.-M.; project administration, K.H.G.; funding acquisition, Y.F.-A. and K.H.G. All authors have read and agreed to the published version of the manuscript.

Funding: This research was funded by the National Institute on Minority Health and Health Disparities (NIMHD) and the National Institute of Allergy and Infectious Diseases (NIAID) of the National Institutes of Health under award number U54MD007587. I.D.-M. acknowledges the National Aeronautics and Space Administration Cooperative Agreement no. 80NSSC20M0052 (Puerto Rico Space Grant Consortium). The content is solely the authors' responsibility and does not necessarily represent the official views of the National Institutes of Health or the National Aeronautics and Space Administration.

Institutional Review Board Statement: All necessary approvals from the Institutional Animal Care and Use Committee (IACUC) were in place for the performed research: Assurance ID number D16-00343, IACUC Protocol Universal Number 048-2021-08-01-PHA-IBC.

Informed Consent Statement: Not applicable.

Data Availability Statement: Not applicable.

Acknowledgments: The authors are very grateful to Bismark Madera, M.T. for his outstanding work and dedication to the confocal imaging experiments. The confocal microscopy experiments were performed in the Neuroimaging Facilities supported by NASA Space Grant (Puerto Rico Space Grant Consortium) 80NSSC20M0052 and COBRE P20GM103642. Irivette Dominguez-Martinez received the NASA PR Space Grant Doctoral Fellowship (NASA Grant 80NSSC20M0052).

Conflicts of Interest: The authors declare no conflict of interest. The funders had no role in the design of the study; in the collection, analyses, or interpretation of data; in the writing of the manuscript, or in the decision to publish the results.

\section{References}

1. Zappa, C.; Mousa, S.A. Non-small cell lung cancer: Current treatment and future advances. Transl. Lung Cancer Res. 2016, 5, 288-300. [CrossRef] [PubMed]

2. Siegel, R.L.; Miller, K.D.; Fuchs, H.E.; Jemal, A. Cancer statistics, 2021. CA Cancer J. Clin. 2021, 71, 7-33. [CrossRef] [PubMed]

3. Senapati, S.; Mahanta, A.K.; Kumar, S.; Maiti, P. Controlled drug delivery vehicles for cancer treatment and their performance. Signal Transduct. Target. Ther. 2018, 3, 7. [CrossRef]

4. $\quad$ Park, J.H.; Park, S.A.; Lee, Y.J.; Park, H.W.; Oh, S.M. PBK attenuates paclitaxel-induced autophagic cell death by suppressing p53 in H460 non-small-cell lung cancer cells. FEBS Open Bio 2020, 10, 937-950. [CrossRef]

5. Duarte, M.L.; de Moraes, E.; Pontes, E.; Schluckebier, L.; de Moraes, J.L.; Hainaut, P.; Ferreira, C.G. Role of p53 in the induction of cyclooxygenase-2 by cisplatin or paclitaxel in non-small cell lung cancer cell lines. Cancer Lett. 2009, 279, 57-64. [CrossRef] 
6. Fregoni, M.M.; Nelli, F.; Riccardi, F.; di Isernia, G.; Costanzo, R.; Rocco, G.; Daniele, G.; Signoriello, S.; Piccirillo, M.C.; Gallo, C. Cisplatin-Based First-Line Treatment of Elderly Patients with Advanced Non-Small-Cell Lung Cancer: Joint Analysis of MILES-3 and MILES-4 Phase III Trials. J. Clin. Oncol. 2018, 36, 2585-2592. [CrossRef]

7. Aubrey, B.J.; Kelly, G.L.; Janic, A.; Herold, M.J.; Strasser, A. How does p53 induce apoptosis and how does this relate to p53-mediated tumour suppression? Cell Death Differ. 2018, 25, 104-113. [CrossRef]

8. Greulich, H. The genomics of lung adenocarcinoma: Opportunities for targeted therapies. Genes Cancer 2010, 1, 1200-1210. [CrossRef]

9. Vazquez, A.; Bond, E.E.; Levine, A.J.; Bond, G.L. The genetics of the p53 pathway, apoptosis and cancer therapy. Nat. Rev. Drug Discov. 2008, 7, 979-987. [CrossRef]

10. Baig, S.; Seevasant, I.; Mohamad, J.; Mukheem, A.; Huri, H.Z.; Kamarul, T. Potential of apoptotic pathway-targeted cancer therapeutic research: Where do we stand? Cell Death Dis. 2016, 7, e2058. [CrossRef]

11. Serna, N.; Sánchez-García, L.; Unzueta, U.; Díaz, R.; Vázquez, E.; Mangues, R.; Villaverde, A. Protein-based therapeutic killing for cancer therapies. Trends Biotechnol. 2018, 36, 318-335. [CrossRef] [PubMed]

12. Yamada, Y.; Harashima, H. Mitochondrial drug delivery systems for macromolecule and their therapeutic application to mitochondrial diseases. Adv. Drug Deliv. Rev. 2008, 60, 1439-1462. [CrossRef] [PubMed]

13. Yadav, N.; Gogada, R.; O’Malley, J.; Gundampati, R.K.; Jayanthi, S.; Hashmi, S.; Lella, R.; Zhang, D.; Wang, J.; Kumar, R.; et al Molecular insights on cytochrome $\mathrm{c}$ and nucleotide regulation of apoptosome function and its implication in cancer. Biochim. Biophys. Acta Mol. Cell Res. 2020, 1867, 118573. [CrossRef] [PubMed]

14. Méndez, J.; Morales Cruz, M.; Delgado, Y.; Figueroa, C.M.; Orellano, E.A.; Morales, M.; Monteagudo, A.; Griebenow, K. Delivery of Chemically Glycosylated Cytochrome c Immobilized in Mesoporous Silica Nanoparticles Induces Apoptosis in HeLa Cancer Cells. Mol. Pharm. 2014, 11, 102-111. [CrossRef] [PubMed]

15. Alkhuriji, A.F.; Alsaiari, S.G.; Alomar, S.Y.; Alnafjan, A.A.; Alobaid, H.; El-Khadragy, M.F. Effect of mesenchymal stem cells on cytochrome-c release and inflammation in colon cancer induced by 1, 2-dimethylhydrazine in Wistar albino rats. Biosci. Rep. 2021, 41, BSR20204356. [CrossRef] [PubMed]

16. Crider, K.S.; Yang, T.P.; Berry, R.J.; Bailey, L.B. Folate and DNA methylation: A review of molecular mechanisms and the evidence for folate's role. Adv. Nutr. 2012, 3, 21-38. [CrossRef] [PubMed]

17. Scaranti, M.; Cojocaru, E.; Banerjee, S.; Banerji, U. Exploiting the folate receptor $\alpha$ in oncology. Nat. Rev. Clin. Oncol. 2020, 17, 349-359. [CrossRef]

18. O'Shannessy, D.J.; Yu, G.; Smale, R.; Fu, Y.-S.; Singhal, S.; Thiel, R.P.; Somers, E.B.; Vachani, A. Folate receptor alpha expression in lung cancer: Diagnostic and prognostic significance. Oncotarget 2012, 3, 414. [CrossRef]

19. Iwakiri, S.; Sonobe, M.; Nagai, S.; Hirata, T.; Wada, H.; Miyahara, R. Expression status of folate receptor $\alpha$ is significantly correlated with prognosis in non-small-cell lung cancers. Ann. Surg. Oncol. 2008, 15, 889-899. [CrossRef]

20. Shi, H.; Guo, J.; Li, C.; Wang, Z. A current review of folate receptor alpha as a potential tumor target in non-small-cell lung cancer. Drug Des. Dev. Ther. 2015, 9, 4989. [CrossRef]

21. Hanahan, D.; Weinberg, R.A. The hallmarks of cancer. Cell 2000, 100, 57-70. [CrossRef]

22. Kobayashi, H.; Watanabe, R.; Choyke, P.L. Improving conventional enhanced permeability and retention (EPR) effects; what is the appropriate target? Theranostics 2013, 4, 81-89. [CrossRef] [PubMed]

23. Suk, J.S.; Xu, Q.; Kim, N.; Hanes, J.; Ensign, L.M. PEGylation as a strategy for improving nanoparticle-based drug and gene delivery. Adv. Drug Deliv. Rev. 2016, 99, 28-51. [CrossRef] [PubMed]

24. Geng, Y.; Dalhaimer, P.; Cai, S.; Tsai, R.; Tewari, M.; Minko, T.; Discher, D.E. Shape effects of filaments versus spherical particles in flow and drug delivery. Nat. Nanotechnol. 2007, 2, 249-255. [CrossRef] [PubMed]

25. Alves, I.D.; Jiao, C.Y.; Aubry, S.; Aussedat, B.; Burlina, F.; Chassaing, G.; Sagan, S. Cell biology meets biophysics to unveil the different mechanisms of penetratin internalization in cells. Biochim. Biophys. Acta 2010, 1798, 2231-2239. [CrossRef] [PubMed]

26. Petros, R.A.; DeSimone, J.M. Strategies in the design of nanoparticles for therapeutic applications. Nat. Rev. Drug Discov. 2010, 9, 615-627. [CrossRef]

27. Santra, S.; Kaittanis, C.; Perez, J.M. Cytochrome C encapsulating theranostic nanoparticles: A novel bifunctional system for targeted delivery of therapeutic membrane-impermeable proteins to tumors and imaging of cancer therapy. Mol. Pharm. 2010, 7, 1209-1222. [CrossRef]

28. Morales-Cruz, M.; Cruz-Montañez, A.; Figueroa, C.M.; González-Robles, T.; Davila, J.; Inyushin, M.; Loza-Rosas, S.A.; Molina, A.M.; Muñoz-Perez, L.; Kucheryavykh, L.Y. Combining stimulus-triggered release and active targeting strategies improves cytotoxicity of cytochrome c nanoparticles in tumor cells. Mol. Pharm. 2016, 13, 2844-2854. [CrossRef]

29. Barcelo-Bovea, V.; Dominguez-Martinez, I.; Joaquin-Ovalle, F.; Amador, L.A.; Castro-Rivera, E.; Medina-Álvarez, K.; McGoron, A.; Griebenow, K.; Ferrer-Acosta, Y. Optimization and Characterization of Protein Nanoparticles for the Targeted and Smart Delivery of Cytochrome c to Non-Small Cell Lung Carcinoma. Cancers 2020, 12, 1215. [CrossRef]

30. Biswas, S.; Torchilin, V.P. Nanopreparations for organelle-specific delivery in cancer. Adv. Drug Deliv. Rev. 2014, 66, 26-41. [CrossRef]

31. Kellar, A.; Egan, C.; Morris, D. Preclinical murine models for lung cancer: Clinical trial applications. BioMed Res. Int. 2015, $2015,621324$. [CrossRef] [PubMed]

32. Caesar, C.E.B.; Esbjörner, E.K.; Lincoln, P.; Nordén, B. Assigning membrane binding geometry of cytochrome c by polarized light spectroscopy. Biophys. J. 2009, 96, 3399-3411. [CrossRef] [PubMed] 
33. Gaucher, C.; Boudier, A.; Bonetti, J.; Clarot, I.; Leroy, P.; Parent, M. Glutathione: Antioxidant properties dedicated to nanotechnologies. Antioxidants 2018, 7, 62. [CrossRef] [PubMed]

34. Monteiro, C.A.P.; Oliveira, A.; Silva, R.C.; Lima, R.R.M.; Souto, F.O.; Baratti, M.O.; Carvalho, H.F.; Santos, B.S.; Cabral Filho, P.E.; Fontes, A. Evaluating internalization and recycling of folate receptors in breast cancer cells using quantum dots. J. Photochem. Photobiol. B 2020, 209, 111918. [CrossRef] [PubMed]

35. Talbot, S.R.; Biernot, S.; Bleich, A.; van Dijk, R.M.; Ernst, L.; Häger, C.; Helgers, S.O.A.; Koegel, B.; Koska, I.; Kuhla, A. Defining body-weight reduction as a humane endpoint: A critical appraisal. Lab. Anim. 2020, 54, 99-110. [CrossRef] [PubMed]

36. Lushchak, V.I. Glutathione homeostasis and functions: Potential targets for medical interventions. J. Amino Acids 2012, 2012, 736837. [CrossRef]

37. Elkhodiry, M.A.; Husseini, G.A.; Velluto, D. Targeting the folate receptor: Effects of conjugating folic acid to DOX loaded polymeric micelles. Anticancer Agents Med. Chem. (Former. Curr. Med. Chem.-Anti-Cancer Agents) 2016, 16, 1275-1280. [CrossRef]

38. Fernández, M.; Javaid, F.; Chudasama, V. Advances in targeting the folate receptor in the treatment/imaging of cancers. Chem. Sci. 2018, 9, 790-810. [CrossRef]

39. Li, W.; Chen, C.; Ye, C.; Wei, T.; Zhao, Y.; Lao, F.; Chen, Z.; Meng, H.; Gao, Y.; Yuan, H. The translocation of fullerenic nanoparticles into lysosome via the pathway of clathrin-mediated endocytosis. Nanotechnology 2008, 19, 145102. [CrossRef]

40. Gonda, A.; Zhao, N.; Shah, J.V.; Calvelli, H.R.; Kantamneni, H.; Francis, N.L.; Ganapathy, V. Engineering tumor-targeting nanoparticles as vehicles for precision nanomedicine. Med. One 2019, 4, e190021. [CrossRef]

41. Sindhwani, S.; Syed, A.M.; Ngai, J.; Kingston, B.R.; Maiorino, L.; Rothschild, J.; MacMillan, P.; Zhang, Y.; Rajesh, N.U.; Hoang, T.; et al. The entry of nanoparticles into solid tumours. Nat. Mater. 2020, 19, 566-575. [CrossRef] [PubMed]

42. Longmire, M.R.; Ogawa, M.; Choyke, P.L.; Kobayashi, H. Biologically optimized nanosized molecules and particles: More than just size. Bioconj. Chem. 2011, 22, 993-1000. [CrossRef] [PubMed]

43. Aghajani, M.H.; Pashazadeh, A.M.; Mostafavi, S.H.; Abbasi, S.; Hajibagheri-Fard, M.-J.; Assadi, M.; Aghajani, M. Size Control in the Nanoprecipitation Process of Stable Iodine (127 I) Using Microchannel Reactor-Optimization by Artificial Neural Networks Aaps Pharmscitech 2015, 16, 1059-1068. [CrossRef]

44. Molina, A.M.; Morales-Cruz, M.; Benítez, M.; Berríos, K.; Figueroa, C.M.; Griebenow, K. Redox-sensitive crosslinking enhances albumin nanoparticle function as delivery system for photodynamic cancer therapy. J. Nanomed. Nanotechnol. 2016, 6, 294. [CrossRef] [PubMed]

45. Müller, F.n.; Graziadei, A.; Rappsilber, J. Quantitative photo-crosslinking mass spectrometry revealing protein structure response to environmental changes. Anal. Chem. 2019, 91, 9041-9048. [CrossRef] [PubMed]

46. Parrish, A.B.; Freel, C.D.; Kornbluth, S. Cellular mechanisms controlling caspase activation and function. Cold Spring Harb. Perspect. Biol. 2013, 5, a008672. [CrossRef]

47. Yu, T.; Wang, X.; Purring-Koch, C.; Wei, Y.; McLendon, G.L. A mutational epitope for cytochrome C binding to the apoptosis protease activation factor-1. J. Biol. Chem. 2001, 276, 13034-13038. [CrossRef]

48. Sakai, Y.; Sasahira, T.; Ohmori, H.; Yoshida, K.; Kuniyasu, H. Conjugated linoleic acid reduced metastasized LL2 tumors in mouse peritoneum. Virchows Arch. 2006, 449, 341-347. [CrossRef]

49. Papageorgiou, A.; Stravoravdi, P.; Sahpazidou, D.; Natsis, K.; Chrysogelou, E.; Toliou, T. Effect of navelbine on inhibition of tumor growth, cellular differentiation and estrogen receptor status on Lewis lung carcinoma. Chemotherapy 2000, 46, 188-194. [CrossRef]

50. Delbridge, A.R.; Valente, L.J.; Strasser, A. The role of the apoptotic machinery in tumor suppression. Cold Spring Harb. Perspect. Biol. 2012, 4, a008789. [CrossRef]

51. Majtnerova, P.; Rousar, T. An overview of apoptosis assays detecting DNA fragmentation. Mol. Biol. Rep. 2018, 45, 1469-1478. [CrossRef]

52. Lee, J.H.; Li, Y.C.; Ip, S.W.; Hsu, S.C.; Chang, N.W.; Tang, N.Y.; Yu, C.S.; Chou, S.T.; Lin, S.S.; Lino, C.C.; et al. The role of Ca ${ }^{2+}$ in baicalein-induced apoptosis in human breast MDA-MB-231 cancer cells through mitochondria- and caspase-3-dependent pathway. Anticancer Res. 2008, 28, 1701-1711. [PubMed]

53. Makvandi, P.; Chen, M.; Sartorius, R.; Zarrabi, A.; Ashrafizadeh, M.; Dabbagh Moghaddam, F.; Ma, J.; Mattoli, V.; Tay, F.R. Endocytosis of abiotic nanomaterials and nanobiovectors: Inhibition of membrane trafficking. Nano Today 2021, 40, 101279. [CrossRef] [PubMed]

54. Rizvi, S.A.A.; Saleh, A.M. Applications of nanoparticle systems in drug delivery technology. Saudi Pharm. J. 2018, 26, 64-70. [CrossRef] [PubMed]

55. Lu, J.; Zhao, W.; Huang, Y.; Liu, H.; Marquez, R.; Gibbs, R.B.; Li, J.; Venkataramanan, R.; Xu, L.; Li, S. Targeted delivery of doxorubicin by folic acid-decorated dual functional nanocarrier. Mol. Pharm. 2014, 11, 4164-4178. [CrossRef] [PubMed]

56. Liu, F.; Chen, Y.; Li, Y.; Guo, Y.; Cao, Y.; Li, P.; Wang, Z.; Gong, Y.; Ran, H. Folate-receptor-targeted laser-activable poly (lactide-co-glycolic acid) nanoparticles loaded with paclitaxel/indocyanine green for photoacoustic/ultrasound imaging and chemo/photothermal therapy. Int. J. Nanomed. 2018, 13, 5139. [CrossRef] 